IZA DP No. 8236

Cognitive Ability, Character Skills, and Learning to Play Equilibrium: A Level-k Analysis

David Gill

Victoria Prowse

June 2014 


\title{
Cognitive Ability, Character Skills, and Learning to Play Equilibrium: A Level-k Analysis
}

\author{
David Gill \\ Oxford University \\ Victoria Prowse \\ Cornell University \\ and IZA \\ Discussion Paper No. 8236 \\ June 2014 \\ IZA \\ P.O. Box 7240 \\ 53072 Bonn \\ Germany \\ Phone: +49-228-3894-0 \\ Fax: +49-228-3894-180 \\ E-mail: iza@iza.org
}

Any opinions expressed here are those of the author(s) and not those of IZA. Research published in this series may include views on policy, but the institute itself takes no institutional policy positions. The IZA research network is committed to the IZA Guiding Principles of Research Integrity.

The Institute for the Study of Labor (IZA) in Bonn is a local and virtual international research center and a place of communication between science, politics and business. IZA is an independent nonprofit organization supported by Deutsche Post Foundation. The center is associated with the University of Bonn and offers a stimulating research environment through its international network, workshops and conferences, data service, project support, research visits and doctoral program. IZA engages in (i) original and internationally competitive research in all fields of labor economics, (ii) development of policy concepts, and (iii) dissemination of research results and concepts to the interested public.

IZA Discussion Papers often represent preliminary work and are circulated to encourage discussion. Citation of such a paper should account for its provisional character. A revised version may be available directly from the author. 


\section{ABSTRACT \\ Cognitive Ability, Character Skills, and Learning to Play Equilibrium: A Level-k Analysis*}

In this paper we investigate how cognitive ability and character skills influence behavior, success and the evolution of play towards Nash equilibrium in repeated strategic interactions. We study behavior in a $p$-beauty contest experiment and find striking differences according to cognitive ability: more cognitively able subjects choose numbers closer to equilibrium, converge more frequently to equilibrium play and earn more even as behavior approaches the equilibrium prediction. To understand better how subjects with different cognitive abilities learn differently, we estimate a structural model of learning based on level-k reasoning. We find a systematic positive relationship between cognitive ability and levels; furthermore, the average level of more cognitively able subjects responds positively to the cognitive ability of their opponents, while the average level of less cognitively able subjects does not respond. Finally, we compare the influence of cognitive ability to that of character skills, and find that both cognition and personality affect behavior and learning. More agreeable and emotionally stable subjects perform better and learn faster, although the effect of cognitive ability on behavior is stronger than that of character skills.

JEL Classification: C92, C73, D83

Keywords: cognitive ability, character skills, personality traits, level-k, bounded rationality, learning, convergence, non-equilibrium behavior, beauty contest, repeated games, structural modeling, theory of mind, intelligence, IQ, cognition, Raven test

Corresponding author:

Victoria Prowse

Department of Economics

264 Ives Hall

Cornell University

Ithaca, New York, 14853

USA

E-mail: prowse@cornell.edu

\footnotetext{
* A Supplementary Web Appendix provides additional materials. An earlier version of this paper was circulated as Gill and Prowse (2012) under the title "Cognitive ability and learning to play equilibrium: A level-k analysis."
} 


\section{Introduction}

In this paper, we aim to discover how cognitive ability and character skills influence behavior, success and the evolution of play towards Nash equilibrium in repeated strategic interactions. ${ }^{1}$ Many economic interactions are strategic and repeated (the first paragraph of Section 2 provides numerous examples). Given that cognitive ability and character skills vary greatly at the population level, to understand fully the dynamics of how people behave and learn in repeated strategic interactions we need to establish the roles of cognition and character. Despite welldocumented heterogeneity in cognitive ability and character skills, to the best of our knowledge we are the first to study how cognition and character affect how people learn to play equilibrium.

Our experiment was designed to answer the following questions: (i) does cognitive ability influence the way that groups of agents learn to play equilibrium over time when they engage in repeated strategic interaction?; (ii) how do subjects' learning processes depend both on their own cognitive ability and that of their opponents?; (iii) do character skills influence how people learn to play equilibrium?; and (iv) how do the effects of character skills compare to those of cognitive ability?

We first measured the cognitive ability of our 780 subjects using a 60 question non-verbal Raven test. We classified each subject as either of high cognitive ability or of low cognitive ability according to whether her test score was in the top or bottom half of the distribution of scores in her session. We then matched our subjects into groups of three. In own-matched groups, all three members were of the same cognitive ability type. In cross-matched groups, the three members were of mixed ability (either two high ability and one low ability subject, or vice versa). Subjects found out their own cognitive ability type as well as the ability type of the other two group members. ${ }^{2}$ This design feature allows us to conduct an analysis of how behavior responds to the cognitive ability of opponents.

Each group of three then played the $p$-beauty contest ten times without rematching and with feedback. ${ }^{3}$ In our $p$-beauty contest, the three group members simultaneously chose an integer between 0 and 100 inclusive, and the subject whose choice was closest to $70 \%$ of the average of the three numbers won $\$ 6$. In the unique Nash equilibrium, all subjects choose 0 ; however, the game is well suited to study learning since best responses to non-equilibrium choices are often above 0 , but with repetition behavior tends to move towards equilibrium. Our focus on repeated interaction makes it natural to keep group membership constant over the ten rounds of the experiment; indeed, only with constant groups can we conduct our analysis of how often different groups converge to equilibrium play. We chose a group size of three to maximize the number of independent observations, while ensuring that the game has an interesting strategic

\footnotetext{
${ }^{1}$ We follow Heckman and Kautz (2014) in using the term 'character skills' to describe personal attributes that are sometimes called 'personality traits' or 'non-cognitive' skills. Heckman and Kautz (2014) note that character skills can be shaped and changed over the life-cycle, while the term 'traits' conveys "a sense of immutability or permanence."

${ }^{2}$ As far as possible the instructions used neutral language, and so did not refer to 'high ability', 'low ability', 'winning', and so on. Controlling for a subject's own Raven test score, we find no evidence that the allocation to cognitive ability type per se has any influence on choices or earnings (see Appendix A for details of the analysis).

${ }^{3}$ Real-world parallels to $p$-beauty contests include timing games in financial and labor markets. During a bubble or in a job market, there is an advantage to trading or making job offers a little earlier than competitors, but moving too early is costly (in terms of lost profit on the upward wave of the bubble or missing out on new information about job candidates). Roth and Xing (1994) provide evidence of slow unraveling of the timing of offers in entry-level professional job markets.
} 
component (with a group size of just two, choosing zero is weakly dominant).

We find striking differences by cognitive ability: more cognitively able subjects choose numbers closer to equilibrium, converge more frequently to equilibrium play and earn substantially more on average even as behavior approaches the equilibrium prediction. In the final two rounds, all three group members choose the equilibrium action $29 \%$ of the time in own-matched high ability groups, but only $15 \%$ of the time in cross-matched groups and $13 \%$ of the time in ownmatched low ability groups; similar results hold for measures of close-to-equilibrium play.

To help gain insight into the micro-processes that drive these differences, and thus to understand better how subjects with different cognitive abilities learn differently, we estimate a structural model of learning based on level- $k$ reasoning that fits well the differences in behavior according to cognitive ability that we observe in the data. ${ }^{4,5}$ Following Nagel (1995), Stahl (1996) and Duffy and Nagel (1997), we assume that level-0 types "follow the crowd" in the sense that they copy the average group behavior from the previous round, level-1 types best respond to the choices of level-0 types, level- 2 types best respond to the choices of level- 1 types, and so on. We also incorporate a form of rule learning (Stahl, 1996) by including types who switch up one level during the course of the experiment. The model allows subjects' levels to vary in their own cognitive ability and that of their opponents: we find a systematic positive relationship between cognitive ability and levels; furthermore, the average level of more cognitively able subjects responds positively to the cognitive ability of their opponents, while the average level of less cognitively able subjects does not respond.

The estimates of the structural model's parameters also allow us to simulate the earnings of each level- $k$ type, according to subjects' own cognitive ability and that of their opponents. This analysis shows that subjects are constrained in their levels below those that are optimal, but that high cognitive ability subjects leave less money on the table compared to the payoff-maximizing type (the payoff-maximizing type is allowed to vary in subjects' own cognitive ability and that of their opponents). On average, own-matched high ability subjects leave $\$ 4.59$ on the table, cross-matched high ability subjects leave $\$ 4.61$ on the table, own-matched low ability subjects leave $\$ 5.75$ on the table, and cross-matched low ability subjects leave $\$ 7.75$ on the table.

Before the test of cognitive ability, we administered questionnaires to 270 of the 780 subjects to measure seven character skills: openness, conscientiousness, extraversion, agreeableness and emotional stability (the Big Five), grit and Consideration of Future of Consequences (CFC). ${ }^{6}$

\footnotetext{
${ }^{4}$ Methodologically, our structural analysis builds on existing level- $k$ mixture-of-types models estimated using Maximum Likelihood, including Stahl and Wilson (1995), Ho et al. (1998), Costa-Gomes et al. (2001), CostaGomes and Crawford (2006), Crawford and Iriberri (2007a), Crawford and Iriberri (2007b) and Costa-Gomes and Weizsäcker (2008). Structural level- $k$ mixture-of-types models have been applied successfully to study behavior in, for example, guessing games (Costa-Gomes and Crawford, 2006), coordination games (Costa-Gomes et al., 2009) and auctions (Crawford and Iriberri, 2007a), and to analyze the role of beliefs in normal-form games (CostaGomes and Weizsäcker, 2008). The closely related cognitive hierarchy model (Camerer et al., 2004) has been used to study behavior in, e.g., zero-sum betting games (Brocas et al., forthcoming), telecoms markets (Goldfarb and Xiao, 2011) and the Lowest Unique Positive Integer game used by the Swedish national lottery (Östling et al., 2011). See Crawford et al. (2013) for a comprehensive survey of applications of level- $k$ and cognitive hierarchy models.

${ }^{5}$ Our level- $k$ model of learning provides a relatively simple framework that organizes succinctly differences in behavior by cognitive ability. As is the case in all modeling exercises, we cannot rule out the existence of other models with superior or equal ability to fit our sample. Further, we cannot rule out the existence of alternative models that are observationally equivalent to our level- $k$ model of learning.

${ }^{6}$ We measured the Big Five using the Big Five Inventory (John et al., 1991; John et al., 2008). The Grit Scale measures "perseverance and passion for long-term goals" (Duckworth et al., 2007). CFC is a survey-based
} 
The high degree of correlation between our seven measures justifies the construction of a smaller number of uncorrelated factors. A principal component factor analysis gives three factors, which explain two-thirds of the variance: Factor 1 mainly captures conscientiousness, grit and CFC; Factor 2 mainly captures agreeableness and emotional stability; while Factor 3 mainly captures openness, extraversion and CFC.

We find that both cognitive ability and character skills influence behavior, success and learning in our repeated strategic interaction. Subjects with a higher Raven test score (who are more cognitively able) and a higher Factor 2 score (who are more agreeable and emotionally stable) choose numbers closer to equilibrium, earn more and, within the context of our level- $k$ model of learning, adopt higher level- $k$ choice rules. We also find that both cognitive ability and character skills influence learning at the group level: groups with higher cognitive ability on average and higher Factor 2 on average end up closer to the Nash equilibrium in the last few rounds. As we discuss in more detail in the final paragraph of Section 2, recent evidence links agreeableness to a better theory of mind, thus providing a channel through which agreeableness might help performance in settings like ours that require strategic reasoning, and shows that emotional stability aids performance in more complex tasks.

The impact of cognitive ability on behavior is about $75 \%$ bigger than that of character skills, but the estimated influence of cognitive ability does not depend on whether we control for character skills, and vice versa. Interestingly, we also find that marginal changes in cognitive ability mainly affect the behavior of subjects who are already cognitively able, while changes in character skills influence the behavior of subjects who are high or low in cognitive ability.

The contribution of our paper is to investigate how cognitive ability and character skills influence learning to play equilibrium in repeated strategic interactions. In doing so, we extend three established literatures. The first literature studies learning in strategic games, both theoretically and empirically, without considering the influence of cognitive ability or character skills (see Camerer, 2003, for a survey). The second literature studies the relationship between cognitive ability and behavior in strategic games without considering the dynamics of how people learn over time to play equilibrium. ${ }^{7}$ The third literature studies the relationship between character skills and behavior in strategic games, again without considering how people learn to play equilibrium. ${ }^{8}$ A further innovation of our paper is to study how learning behavior varies in the

measure of time preference (Strathman et al., 1994).

${ }^{7}$ In one-shot beauty contest games, Burnham et al. (2009) and Brañas-Garza et al. (2012) find that subjects with higher cognitive ability choose lower numbers, while Agranov et al. (2011) find that, when subjects are given time to think about their choices, higher cognitive ability subjects' choices fall more with thinking time. In related dominance-solvable and guessing games, working memory (Rydval et al., 2009) and depths of reasoning in the red hat puzzle (Bayer and Renou, 2012) correlate with behavior. Cognitive ability also influences behavior in public good games (Millet and Dewitte, 2007) and in the prisoner's dilemma (Burks et al., 2009). Schnusenberg and Gallo (2011) run a three-round beauty contest with one winner per round and no monetary incentives (the prize was a small in-class grade improvement), and find that scores in Frederick (2005)'s three-question Cognitive Reflection Test affect choices in the first round only.

${ }^{8}$ In public good games, self-esteem (Kurzban and Houser, 2001) and agreeableness (Volk et al., 2011) generate higher contributions, and more agreeable subjects choose to lead less frequently (Arbak and Villeval, 2013). More self-controlled, more tough-minded and less extraverted subjects offer more in the ultimatum game (Brandstätter and Königstein, 2001). More agreeable subjects send more in a sequential prisoner's dilemma (Rustichini et al., 2012). Higher need-for-cognition and premeditation give rise to fewer dominated choices in dominance-solvable games (Rydval et al., 2009). More neurotic subjects earn more in the stag-hunt game (Al-Ubaydli et al., 2013). In trust games, less anxious (Fahr and Irlenbusch, 2008), less alienated (Johnson et al., 2009), less conscientious, less neurotic and more agreeable (Müller and Schwieren, 2012) subjects are more trusting. Less anxious and more aggressive subjects are more likely to take a risky entry decision (Neeman et al., 2013). This literature does 
cognitive ability of opponents, and to study how subjects' own cognitive ability influences how they respond to their opponents' cognitive ability. This analysis extends a burgeoning literature that studies how strategic play is affected by information about opponent characteristics other than cognitive ability. ${ }^{9}$

The paper proceeds as follows. Section 2 describes how our findings might help to explain the influence of cognition and character on learning and outcomes in markets and other settings. Section 3 describes the experimental design. Section 4 reports descriptive statistics and reduced form regression results that describe how behavior and learning vary with cognitive ability. Section 5 presents the structural analysis of the influence of cognitive ability. Section 6 compares the effects of cognitive ability to those of character skills. Section 7 discusses some broader implications of our findings and concludes.

\section{Opening the black box: How cognition and character influ- ence learning and outcomes in markets and other settings}

Success in markets and other settings often reflects performance after some period of learning to operate successfully in the relevant environment. Our findings regarding the role of cognition and character in explaining behavior and learning in our repeated strategic environment are of interest in themselves, but may also help to open the black box of how intelligence and personality influence learning and outcomes in markets and other settings. Success in repeated strategic interactions like ours requires both analytic reasoning (to deduce how best to respond to beliefs about how others will behave) and a good theory of mind (the ability to judge well the intentions and beliefs of others to predict accurately how others will in fact behave). ${ }^{10}$ To the extent that success in markets and other settings depends on the capacity to learn to use a combination of analytic reasoning skills and the ability to understand well others' patterns of thinking and behavior, our findings may shed light on the underlying processes that explain why cognition and character matter and how they interact. Settings in which successful decision-makers need to learn to combine analytic skills and a good theory of mind include sequences of market entry, exit

not focus on how character skills influence learning to play equilibrium, although Boone et al. (2002) find that sufficient repetition allows subjects with an external locus of control to become more cooperative in the prisoner's dilemma.

${ }^{9} \mathrm{~A}$ small literature looks at the effects of information about how much experience opponents have of the type of strategic reasoning required in the game being studied. Notably, Agranov et al. (2012) find that, in a one-shot beauty contest, inexperienced undergraduates shift to higher level- $k$ types on average when they play against graduates with some experience of the game, while Le Coq and Sturluson (2012) find that play in a Cournot game shifts with the experience of opponents in the game. Palacios-Huerta and Volij (2009) find an effect of subjects' own experience of backward-induction reasoning (chess players versus students) and the experience of their opponents (chess player or student opponent) on behavior in a repeated backward-induction (the centipede) game. In a one-shot field setting, Palacios-Huerta and Volij (2009) find that chess players playing against chess players in the centipede game behave differently from students playing students, although Levitt, List, and Sadoff (2011) fail to replicate this result.

${ }^{10}$ According to Coricelli and Nagel (2009), theory of mind is 'the ability to think about others' thoughts and mental states to predict their intentions and actions", and playing the beauty contest against humans rather than a computer "activated areas commonly associated with theory of mind or mentalizing-thinking about other people's minds." Ohtsubo and Rapoport (2006) argue that "one of the most important uses of the theory-of-mind ability is the strategic reasoning used to outwit or manipulate others." Some games require only analytic reasoning: for example, Dufwenberg et al. (2010), Gneezy et al. (2010) and Cardella (2012) study how players in Race games learn their less-than-obvious dominant strategy. In contrast, the beauty contest requires both analytic reasoning and a good theory of mind. 
and expansion decisions, repeated procuring or selling items via auctions, determining optimal pricing strategies in markets with dynamic price competition, engaging in repeated rounds of hiring or job searching, competing within firms for promotions and bonuses, managing longterm employee relationships, and predicting compatibility with potential partners in long-term relationships such as marriage or supply agreements. More generally, a combination of analytic skills and good theory of mind will matter in any complex environment or task in which learning to predict how others (e.g., rival firms, subordinates, supervisors, teammates, potential partners) think and behave is important for performance. In many professions, learning to use these skills will play a crucial role in determining labor market outcomes and career success. A good theory of mind might also help people to predict how they themselves will adapt to and perform in new environments, and hence allow better sorting in educational and career choices.

Existing studies find a relationship between cognitive ability and the capacity to learn to perform well in the labor market. Schmidt et al. (1986) find that learning through experience matters for job performance, and that cognitive ability speeds up the process of job learning. In a similar vein, Unger et al. (2009) find that more cognitively able entrepreneurs engage in more learning, which in turn helps their businesses grow faster. Cognitive ability also improves job training performance (see Schmidt and Hunter, 2004, for a survey of the evidence). Schmidt et al. (1988) find that even after a period of accumulating experience, cognitive ability continues to matter for job performance, while the findings of McDaniel (1985, as reported in Schmidt and Hunter, 2004, Table 4) provide evidence that the relationship between cognitive ability and job performance becomes stronger with more experience. This mirrors our finding that the difference in performance between high cognitive ability and low cognitive ability subjects, as measured by earnings, becomes bigger in the second half of our experiment. Hunter and Hunter (1984) show that the power of cognitive ability to predict job performance increases with job complexity; this suggests that cognitive ability matters more in complex environments that require the ability to combine different types of intellectual skills, such as analytic reasoning and a good theory of mind.

The relationship between cognitive ability and learning is not limited to labor markets. Many psychologists and psychometricians consider that there is a close relationship between intelligence and a general capacity to learn. ${ }^{11}$ For example, Jensen (1989)'s survey concludes that performance on learning tasks and on conventional tests of intelligence both reflect the general factor $g$ common to all cognitive abilities, and that, furthermore, the relationship between learning and intelligence is stronger when the learning calls forth mental effort, is insightful (that is, it involves 'catching on' or 'getting the idea'), is sufficiently complex, and the learning trials allow the subject time to think. More recently, cognitive ability has been found to correlate with learning in artificial grammar, associative stimulus-response, process control and memory tasks in the laboratory (Alexander and Smales, 1997; Gonzalez, 2004; Williams and Pearlberg, 2006;

\footnotetext{
${ }^{11}$ Early instances include Colvin (1921) and Dearborn (1921). According to Colvin (1921): "On the whole, I consider the most helpful viewpoint from which to consider intelligence is that it is equivalent to the capacity to learn. An individual possesses intelligence in so far as he has learned, or can learn to adjust himself to his environment... It must be remembered that even the ability to think in a sustained and logical manner is based on having learned how to think." According to Dearborn (1921): "The commonly accepted definition of intelligence such as the capacity to learn or to profit by experience evidently involves a description of the nature of the individual and his reactions to the environment... For practical reasons most tests now in common use are not tests of the capacity to learn, but are tests of what has been learned."
} 
Gebauer and Mackintosh, 2007; Kaufman et al., 2009). Danner et al. (2011) find that cognitive ability simultaneously predicts professional success and success at learning an artificial grammar. A link between cognitive ability and learning also exists in educational settings: in particular, cognitive ability helps to predict schooling attainment (e.g., Neisser et al., 1996; Heckman et al., 2006; Cunha et al., 2010; Burks et al., 2014; Heckman et al., 2014).

Our finding that both cognitive ability and character skills influence behavior and learning in our strategic setting contributes to the literature on how intelligence and personality interact to determine performance and achievement, and helps to identify some of the underlying mechanisms that might be at play in markets and other settings. ${ }^{12}$ Our results mirror those of recent studies that show that both cognitive ability and character skills help to predict outcomes and behavior such as wages, workplace performance, educational attainment, marital status and the extent of job searching (Boudreau et al., 2001; Higgins et al., 2007; Heckman et al., 2006; Mueller and Plug, 2006; Duckworth et al., 2007; Cunha et al., 2010 Lindqvist and Vestman, 2011; Burks et al., 2014; Heckman et al., 2014). To the extent that these outcomes and behaviors reflect a combination of analytic reasoning and the ability to understand well the intentions and beliefs of others, our results suggest one mechanism by which cognition and character may jointly be driving them. Our finding that the effect of cognitive ability is stronger than that of character skills echoes the conclusion of Schmidt and Hunter (2004)'s survey that although both cognitive ability and personality predict job and training performance, cognitive ability has the greater impact. Consonant with our finding that marginal increases in cognitive ability matter more for subjects who are already cognitively able, while changes in character skills affect the behavior of high and low cognitive ability subjects, Lindqvist and Vestman (2011) find that the marginal return to cognitive ability in terms of wages in the labor market increases in cognitive ability, and that the return to cognitive ability relative to the return to noncognitive ability is higher for skilled workers.

Finally, our finding that more agreeable and emotionally stable subjects perform better and learn faster in our strategic environment may be related to existing studies on the relationship between these character skills and performance in experimental tasks and in the labor market. Emotional stability and (one of its facets) low anxiety aid performance on more complex experimental tasks (Eysenck, 1985; Szymura and Wodniecka, 2003), while less anxious individuals tend to be found in jobs of higher complexity (Spector et al., 1995) and more emotionally stable individuals report fewer lapses of attention (Flehmig et al., 2007). Consistent with our experimental results, in the labor market emotional stability increases wages (Nyhus and Pons, 2005; Heineck, 2011), job performance (Salgado, 1997) and career success (Judge et al., 1999). Agreeableness correlates positively with the ability to make correct inferences about what others know, what others know about what others know and higher levels of reasoning about others' knowledge (Nettle and Liddle, 2008) and with brain volume in regions that process information about the intentions and beliefs of others (DeYoung et al., 2010). This suggests that agree-

\footnotetext{
${ }^{12}$ Duckworth et al. (2007) note that: "Whereas personality and IQ represent independently flourishing literatures, few contemporary investigations have incorporated both kinds of measures. Thus, we have learned surprisingly little about how personality traits and intelligence are related and about their relative contributions to performance... in general, psychology has ignored the recommendations of Wechsler (1940) and R. B. Cattell and Butcher (1968), who cautioned that the independent study of either noncognitive or cognitive individual differences, to the exclusion of the other, would be impoverished."
} 
ableness is associated with a better theory of mind, which in turn should help performance in settings that require strategic reasoning. The evidence on the relationship between agreeableness and labor market performance is mixed, although Salgado (1997)'s meta-study concludes that agreeableness correlates positively with performance in job training. ${ }^{13}$

\section{Experimental design}

We ran 37 experimental sessions at the University of Arizona's Experimental Science Laboratory (ESL), all conducted on weekdays between November 2010 and March 2011 and in January 2014, and lasting approximately 75 minutes. 18 or 24 student subjects participated in each session, with 780 participants in total. ${ }^{14}$ The participants were drawn from the ESL subject pool, which is managed using a bespoke online recruitment system. We excluded any graduate students in economics. Seating positions were randomized. The experimental instructions (see the Supplementary Web Appendix) were provided to each subject on their computer screen and were read aloud to the subjects. Questions were answered privately. Each subject was paid a show-up fee of $\$ 5.00$ and earned an average of a further $\$ 20.00$ during the experiment (all payments were in U.S. dollars). Subjects were paid privately in cash. The experiment was programmed in z-Tree (Fischbacher, 2007).

\subsection{The test of cognitive ability}

Each session consisted of a test of cognitive ability followed by repeated play of the $p$-beauty contest (Nagel, 1995). (The sessions that we ran in January 2014 also included questionnaires to measure character skills that were administered before the test of cognitive ability: Section 6 provides the details of the measures and analysis of the impact of character skills.) In more detail, each session included a 30 minute computerized test of cognitive ability using Raven's Progressive Matrices. The Raven test, which consists of non-verbal multiple choice questions, is recognized as a leading measure of analytic intelligence (Carpenter et al., 1990; Gray and Thompson, 2004, Box 1, p. 472). ${ }^{15}$ In economics, Raven test scores have been found to correlate positively with fewer Bayesian updating errors (Charness et al., 2011) and with more accurate beliefs (Burks et al., 2009). Each question asks the subjects to identify the missing element that completes a visual pattern. We used the Standard Progressive Matrices Plus version of the Raven test (the level of difficulty lies between that of the Standard Progressive Matrices and the

\footnotetext{
${ }^{13}$ Some studies find a surprising negative relationship between agreeableness and wages (Nyhus and Pons, 2005; Heineck, 2011); however, Seibert and Kraimer (2001) find that this only holds for occupations that require substantial "people skills", such as serving, speaking and negotiating. One possible explanation is that agreeable people are too nice to negotiate wages effectively (Heineck, 2011).

${ }^{14}$ All sessions were run during the Fall or Spring Semesters. Before running these sessions, we also ran one pilot session without any monetary incentives and two sessions with a different form of the $p$-beauty contest (where the target was $90 \%$ of the mean of the choices) whose results are not reported here.

${ }^{15}$ Carpenter et al. (1990) define analytic intelligence (also sometimes called fluid intelligence, as opposed to crystalized intelligence) as "the ability to reason and solve problems involving new information, without relying extensively on an explicit base of declarative knowledge derived from either schooling or previous experience", and show that Raven test scores discriminate according to the ability to use abstract reasoning and correlate highly with scores on other complex cognitive tasks. Raven et al. (2000, SPM25-SPM37) survey the extensive literature that studies: (i) correlations between Raven test scores and scholastic aptitude and achievement tests and other measures of cognitive ability; and (ii) the internal consistency and test-retest reliability of the Raven test.
} 


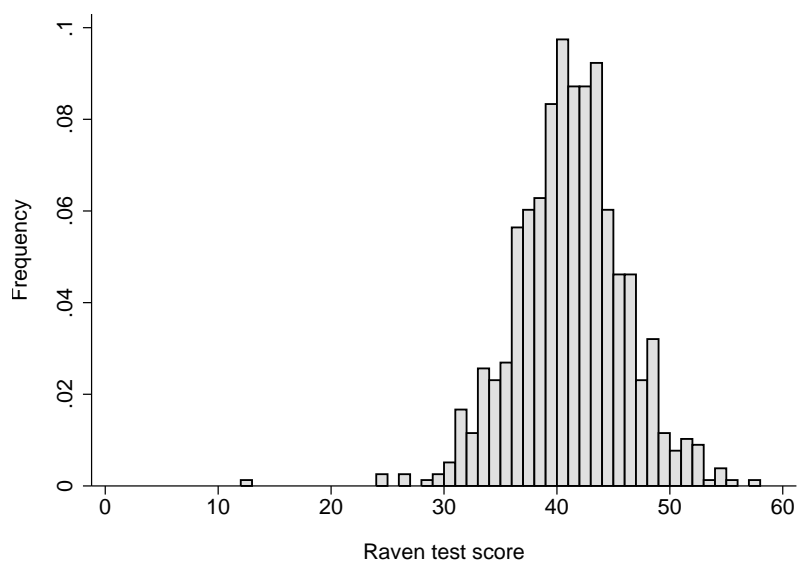

(a) Histogram of Raven test scores.

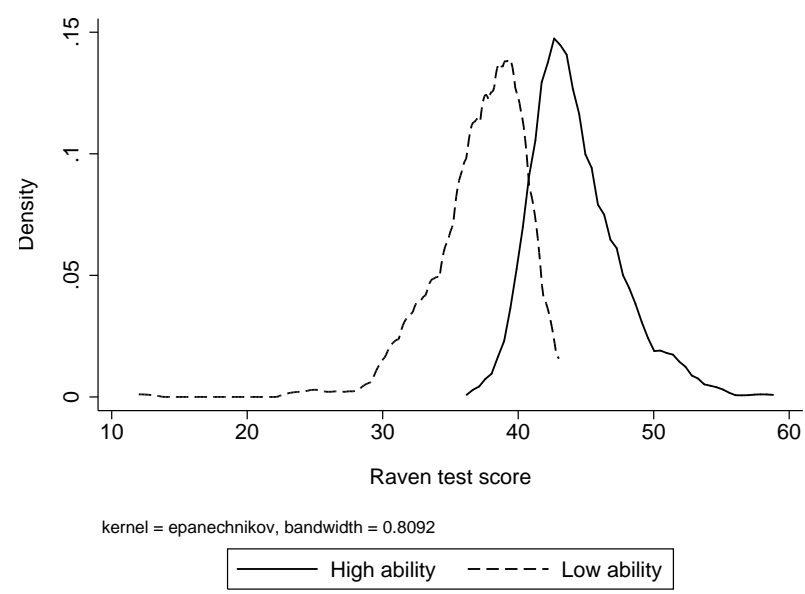

(b) Smoothed densities of Raven test scores.

Figure 1: Histogram and densities of Raven test scores.

Advanced Progressive Matrices), which consists of 60 questions split into 5 parts of increasing difficulty, labeled A-E, with 12 questions in each. We gave the subjects 3 minutes for each of parts $\mathrm{A}$ and $\mathrm{B}$ (which are easier than parts $\mathrm{C}-\mathrm{E}$ ) and 8 minutes for each of parts $\mathrm{C}, \mathrm{D}$ and $\mathrm{E}$. Within each part subjects could move back and forth between the 12 questions in that part and, time permitting, they were allowed to change their previous answers. The subjects were not made aware of what would follow the Raven test until the test was completed.

We did not provide any monetary incentives for completing the Raven test. This is conventional in the psychology and psychometric literatures and avoids the possibility that income effects might spill over from the test to behavior in the $p$-beauty contest. We did, however, tell the subjects that we would inform them privately of their own score at very end of the session. Figure 1(a) shows how the Raven test scores of our subjects were distributed. The mean test score was 40.7, with individual scores ranging from 12 to 58 .

\subsection{Subject matching}

Following the Raven test, each subject was determined to be either (i) of 'high cognitive ability' if her test score was in the top half of the distribution of scores of the subjects in her session or (ii) of 'low cognitive ability' if her test score was in the bottom half of the distribution in her session. Subjects scoring exactly the session median were allocated to ability types so as to ensure an equal number of subjects of each ability type for that session. Figure 1(b) illustrates the densities of the Raven test scores by cognitive ability type. On average, the Raven test score of high ability subjects was 7.0 higher than that of low ability subjects. The range of overlap arises because the median Raven test score varied over sessions, from 37.0 to 43.5. We found no time trend in the median test score over sessions (2-sided $p=0.530)$.

Subjects were then put into groups of 3 . In 'own-matched' sessions, all 3 members of a group were of the same ability type. 450 subjects participated in own-matched sessions, giving 75 groups of 3 high cognitive ability subjects ('own-matched high ability groups') and 75 groups of 3 low cognitive ability subjects ('own-matched low ability groups'). In 'cross-matched' sessions, 
the 3 members of a group were of mixed ability (half the groups were made up of 2 high cognitive ability subjects matched with 1 low cognitive ability subject and the other half were made up of 2 low cognitive ability subjects matched with 1 high cognitive ability subject). 330 subjects participated in cross-matched sessions, giving 110 'cross-matched groups'. Conditional on a subject's cognitive ability type, the allocation to groups was random. The subject matching implies that, on average, high ability subjects face $4 / 3$ more high ability opponents in ownmatched groups than in cross-matched groups, while low ability subjects face $4 / 3$ more high ability opponents in cross-matched groups than in own-matched groups.

We informed each subject of her own cognitive ability type as well as the cognitive ability type of the 2 other members of her group. The instructions (see the Supplementary Web Appendix) did not use the terms 'high ability' or 'low ability'; instead, we referred more neutrally to the top and bottom half of the test scores of all participants in the room. Controlling for a subject's own test score, we find no evidence that the allocation to cognitive ability type per se influenced behavior or earnings in the experiment: Appendix A provides the details of this analysis.

\section{$3.3 \quad p$-beauty contest game}

Each group of 3 then played 10 rounds of the $p$-beauty contest (Nagel, 1995) with $p=0.7$ and without rematching (no rematching allows us to treat behavior across groups as independent). In particular, in every round each group member privately chose an integer between 0 and 100 inclusive (the subjects typed their chosen number into a box rather than selecting it from an on-screen grid). The group member whose chosen number was closest to $70 \%$ of the mean of the 3 numbers chosen by the group members (the 'target') was paid $\$ 6.00$ and the other group members received nothing. In the case of ties, the $\$ 6.00$ was split equally among the winners. To keep the language as neutral as possible, the instructions (see the Supplementary Web Appendix) did not use terms such as 'prize', 'winner', 'loser', 'ties' or 'target'. The unique Nash equilibrium is for all players to choose $0 .{ }^{16}$

Before the start of the first round, we described the number of rounds, the rules of the game and the information feedback the subjects would receive at the end of each round. At the end of every round, each group member was informed of: (i) the numbers chosen by the group members; (ii) the mean of the 3 chosen numbers; (iii) $70 \%$ of the mean (the target); (iv) which group member(s)' number(s) was (were) closest to the target; and (v) how much each group member was paid for the round. ${ }^{17}$ While deciding on their choice of number and also when receiving feedback, the subjects could see a reminder of the rules and of the cognitive ability

\footnotetext{
${ }^{16}$ The game is discrete, and hence this is not true for all values of $p$ (López, 2001). However, it is relatively straightforward to show for our $p=0.7$. A proof starts from the observation that the highest chosen number can never win or tie unless all 3 players choose that number. Suppose that $x_{i} \geq x_{j}$ and $x_{i}>x_{h}$. Let $t$ be the target. If $x_{h} \geq t$, clearly $i$ cannot win or tie. If $x_{h}<t, x_{h}$ is closer to the target than $x_{i}$ if and only if $\left(x_{i}-t\right)-\left(t-x_{h}\right)>0$. When $p=0.7$, this difference equals $\frac{1}{15}\left(8 x_{i}-7 x_{j}+8 x_{h}\right)>0$. Now suppose a Nash equilibrium exists in which the players do not always all choose zero. Let $x^{\max }$ be the highest number that is ever played in equilibrium. $x^{\max }$ cannot be a best response. From the observation, the payoff from $x_{i}=x^{\max }$ is strictly positive if and only if $x_{j}=x_{h}=x^{\max }$ (giving a tie). If that can happen with strictly positive probability, deviating to any lower number is profitable (from the observation giving a win when $x_{j}=x_{h}=x^{\text {max }}$ ). If not, deviating to the lowest number ever chosen by your opponents is profitable (from the observation giving a tie when at least one opponent chooses that number).

${ }^{17}$ In terms of information feedback, our design is close to that of Nagel (1995), where the whole distribution of choices was revealed at the end of each round (but with much larger groups and just 4 repetitions).
} 
type of each member of their group. All interactions were anonymous, but subjects were given labels (X, Y or Z) which were held fixed for the 10 rounds; hence each subject could link the choices in their group to particular opponents whose cognitive ability type they knew.

The subjects had 90 seconds to make their choice in each round. The subjects were told that if they made their choice early, they would still have to wait for the full 90 seconds. If a subject failed to make a choice within 90 seconds, a flashing request prompted an immediate choice. At the end of each round, the subjects could see the feedback information described above for a period of 30 seconds before the next round began.

\section{Reduced form results}

In this section, we report descriptive statistics and reduced form regression results in order to describe how average behavior, the evolution of play over rounds and the group-by-group dynamics of convergence towards equilibrium vary with cognitive ability. In Section 5, we go on to build and estimate a structural model of learning that aims to provide insight into the behavioral mechanisms that underlie the patterns that we describe below.

\subsection{Behavior and earnings in the first round}

We start by reporting briefly how behavior and earnings vary with cognitive ability in the first round. The mean choice of high cognitive ability subjects is 42.9 while that of low cognitive ability subjects is 43.6. The difference of 0.7 is not statistically significant (a regression of $p$ beauty contest choices on cognitive ability type gives a 2 -sided $p=0.626) .{ }^{18}$ To study differences in earnings by cognitive ability we only look at subjects in cross-matched groups: low cognitive ability subjects in own-matched low ability groups must by construction earn as much on average as high cognitive ability subjects in own-matched high ability groups (i.e., $\$ 2.00$ on average in every round). In the first round, cross-matched high ability subjects earn $\$ 0.11$ more than crossmatched low ability subjects (mean earnings in the first round are $\$ 2.00$ ), but the difference is not statistically significant $(2$-sided $p=0.761)$.

\subsection{Behavior across all 10 rounds}

We now consider how behavior varies with cognitive ability across all rounds of the experiment, describing both average behavior across all 10 rounds and the evolution of behavior during the course of the experiment. We first study the behavior of all subjects, and then focus on ownmatched subjects and cross-matched subjects separately. ${ }^{19}$ We study differences in earnings only for cross-matched subjects: as noted in Section 4.1, low cognitive ability subjects in ownmatched low ability groups must by construction earn as much on average as high cognitive ability subjects in own-matched high ability groups (i.e., $\$ 2.00$ on average in every round).

\footnotetext{
${ }^{18}$ Throughout Sections 4.1 and 4.2, all statistical tests are based on Ordinary Least Squares regressions and use heteroskedasticity-consistent standard errors. Apart from the case of first round choices, we cluster at the group level to allow for within-group non-independence. In Section 4.1 the regressions use the 780 subjects observed for 1 round, in Section 4.2.1 they use the 780 subjects observed for 10 rounds, in Section 4.2.2 they use the 450 own-matched subjects observed for either 5 or 10 rounds, and in Section 4.2.3 they use the 330 cross-matched subjects observed for either 5 or 10 rounds.

${ }^{19}$ Appendices C and D provide further analysis of the cross-matched subjects.
} 


\subsubsection{Behavior of all subjects}

Across all 10 rounds of the $p$-beauty contest, the mean choice of high cognitive ability subjects is 17.9 while that of low cognitive ability subjects is 20.1 . Regressing $p$-beauty contest choices on cognitive ability type, we find that the difference of 2.2 is highly statistically significant (2sided $p=0.007)$. Figure 2 shows the round-by-round evolution of mean choices for high and low cognitive ability subjects. We can see that average behavior moves towards the Nash equilibrium for both types. Shortly, we will show that the high ability subjects earn significantly more than low ability subjects (Section 4.2.3) and converge to a greater degree to Nash equilibrium (Section 4.3.2).

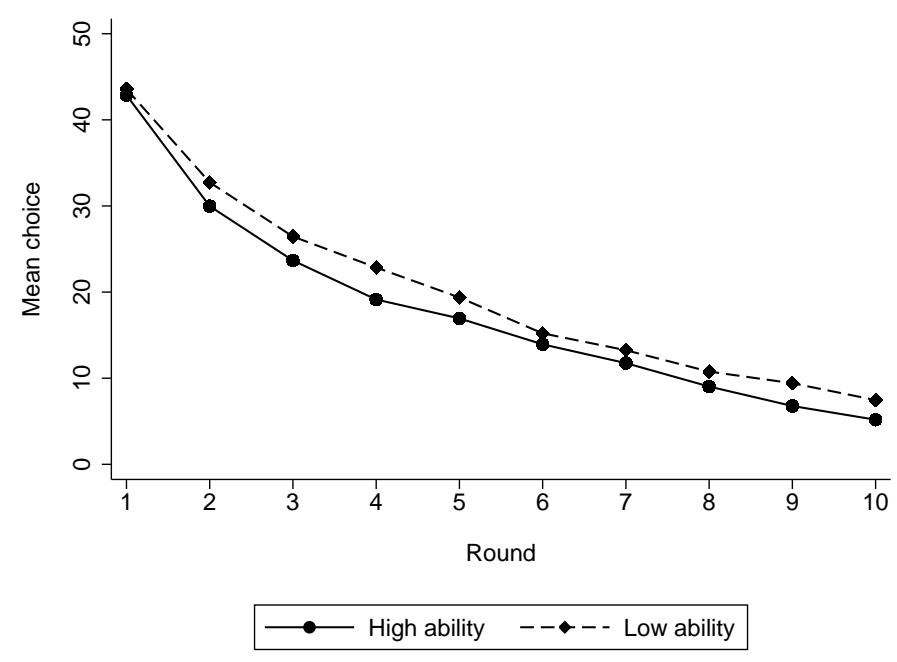

Figure 2: Round-by-round means of $p$-beauty contest choices (all subjects).

\subsubsection{Behavior of own-matched subjects}

The difference in average behavior between high and low cognitive ability subjects is more pronounced for own-matched subjects than for the sample as a whole. Across all 10 rounds, the mean choice of own-matched high cognitive ability subjects is 3.5 lower than that of ownmatched low ability subjects (2-sided $p=0.005)$. Figure 3 shows round-by-round mean choices for own-matched subjects only. In rounds 1-5, choices of own-matched high cognitive ability subjects are on average 3.1 lower than choices of own-matched low ability subjects (2-sided $p=0.025)$. In rounds $6-10$, own-matched high cognitive ability subjects' choices remain lower, by an average of $3.9(2$-sided $p=0.006)$. By the final round, the mean choice of own-matched high cognitive ability subjects falls to 4.3 , while that of own-matched low ability subjects falls to 8.2 . 


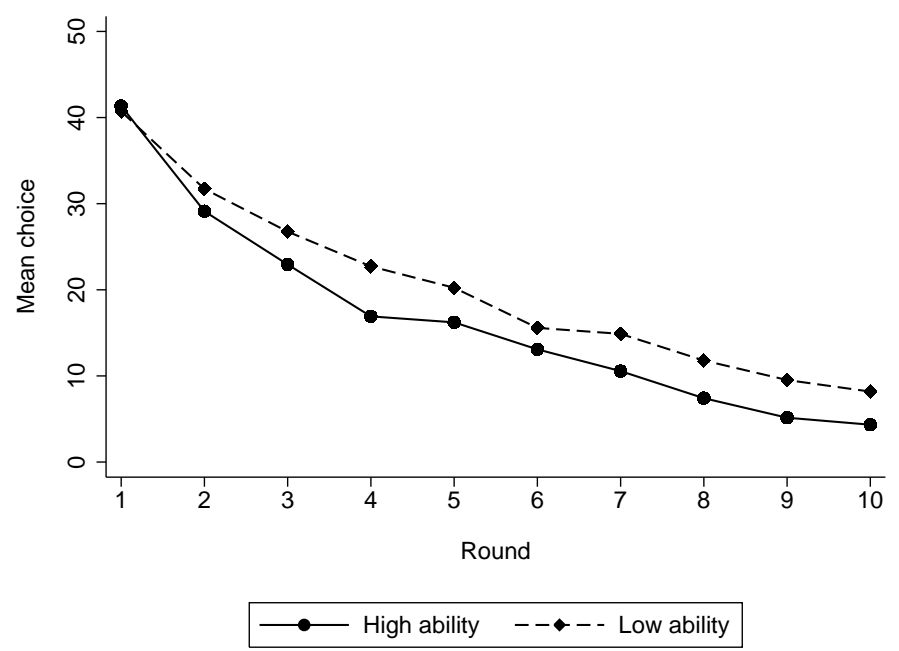

Figure 3: Round-by-round means of $p$-beauty contest choices of own-matched subjects.

\subsubsection{Behavior and earnings of cross-matched subjects}

Across all 10 rounds, the mean choice of cross-matched high cognitive ability subjects is only 0.4 lower than the mean choice of cross-matched low ability subjects, and the difference is not statistically significant $(2$-sided $p=0.653)$. Figure 4 (a) shows round-by-round mean choices for cross-matched subjects only. Cross-matched high and low cognitive ability subjects behave similarly on average in both the first and second halves of the experiment: there is no statistically significant difference in behavior in either rounds $1-5(2$-sided $p=0.181)$ or in rounds $6-10(2-$ sided $p=0.330)$.

Despite the similarity in the average behavior of cross-matched high and low cognitive ability subjects, we find that cross-matched high cognitive ability subjects are more successful in the sense that they earn significantly more money in the experiment. Over the 10 rounds crossmatched high ability subjects earn $\$ 3.56$ more than cross-matched low ability subjects, and the difference is highly statistically significant (2-sided $p=0.007)$.

Figure 4(b) shows how the earnings of cross-matched subjects evolve during the course of the experiment. We can see that: (i) cross-matched high ability subjects earn more than crossmatched low ability subjects in both the first and second halves of the experiment; and that (ii) the earnings difference becomes bigger in the second half. In rounds 1-5, cross-matched high cognitive ability subjects earn $\$ 0.27$ more per round than cross-matched low ability subjects, although the difference is not quite statistically significant (2-sided $p=0.143)$. In rounds 6-10, cross-matched high cognitive ability subjects earn $\$ 0.44$ more per round than cross-matched low ability subjects, and the difference is highly statistically significant $(2$-sided $p=0.003)$. By the final round, the difference in earnings rises to $\$ 0.79$.

Thus earnings diverge in the second half of the experiment, even though average behavior remains similar. Somehow, cross-matched high cognitive ability subjects 'learn' better how to play the game than do cross-matched low cognitive ability subjects. An important aim of the structural analysis described in Section 5 is to provide insight into the mechanisms driving these results. 


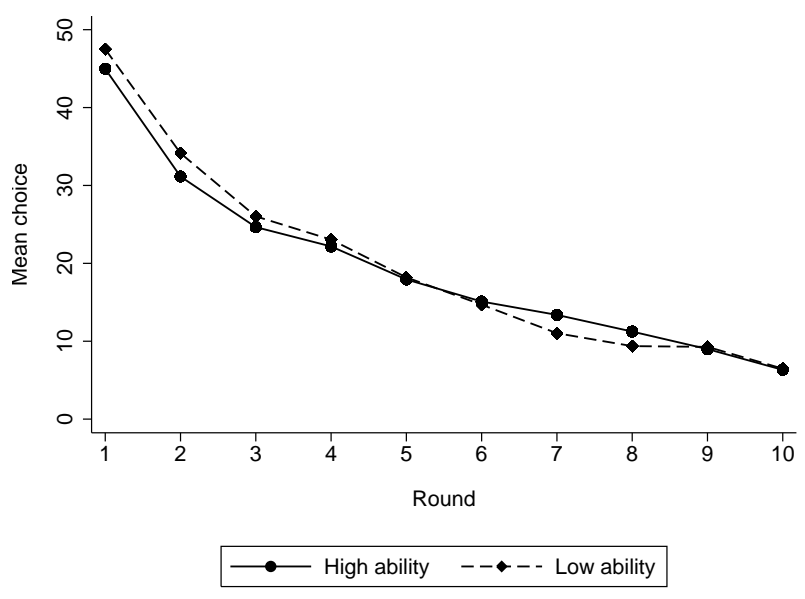

(a) Round-by-round means of choices.

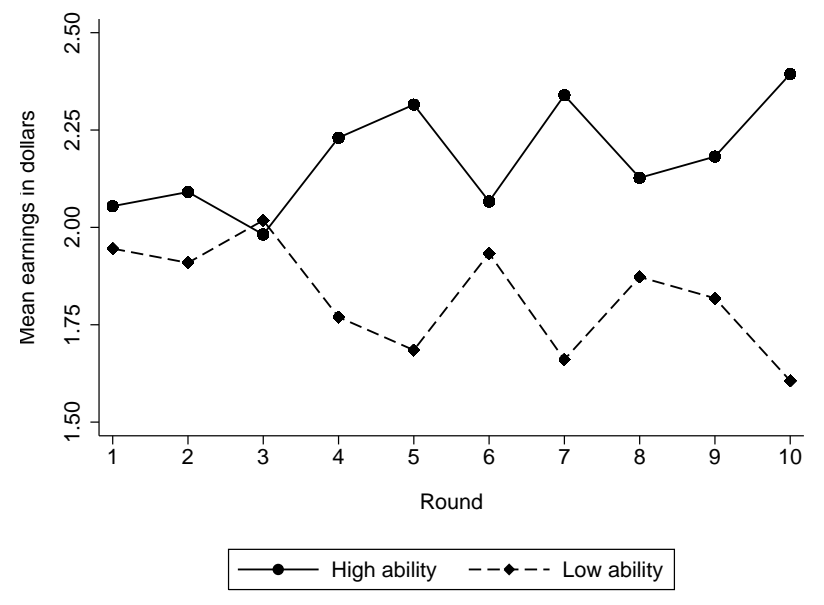

(b) Round-by-round means of earnings.

Figure 4: p-beauty contest choices and earnings of cross-matched subjects.

\subsection{Group-by-group convergence towards equilibrium}

Section 4.2 provides a good overview of how average behavior evolves over time. However, this overview masks a significant amount of group-by-group variation in exactly how play evolves towards equilibrium. In order to better understand how the dynamics of the learning process vary with cognitive ability, in this section we look in more detail at the process of convergence towards Nash equilibrium. We start by providing a visual description of the way in which some individual groups succeed or fail to converge towards equilibrium; we then present results about the proportion of groups that converge and how the degree of convergence varies with group composition.

\subsubsection{Visual description of group-by-group behavior}

Figures 5(a)-5(d) and 6(a)-6(d) give an overview of the group-by-group variation in the dynamics of convergence. Each of the 8 figures shows, for a specific group, how the choices of the 3 group members change round-by-round. The figures also show the winning choice or choices in each round. ${ }^{20}$

Figures 5(a)-5(c) show examples of 3 groups which slowly converge towards equilibrium. No group ever reaches equilibrium in Figures 5(a)-5(c). However, some groups do successfully converge all the way to equilibrium. Figure $5(\mathrm{~d})$ shows an own-matched high ability group in which convergence to equilibrium is almost immediate: by the fourth round all 3 group members choose 0 , and all 3 then stick to the equilibrium choice for the remainder of the experiment. Figure 6(a) shows a cross-matched group in which behavior also converges to equilibrium, although not as fast. As we will see shortly in Section 4.3.2, convergence is much more common when all 3 members of the group are of high cognitive ability.

Convergence towards equilibrium is not the only pattern that we observe. Figures 6(b) and $6(\mathrm{c})$ show groups in which behavior does not move discernibly towards equilibrium. In both cases, high choices by some of the subjects seem to disturb the learning process. However,

\footnotetext{
${ }^{20}$ The Supplementary Web Appendix contains figures illustrating the dynamics of convergence for each of the 260 groups in our sample.
} 


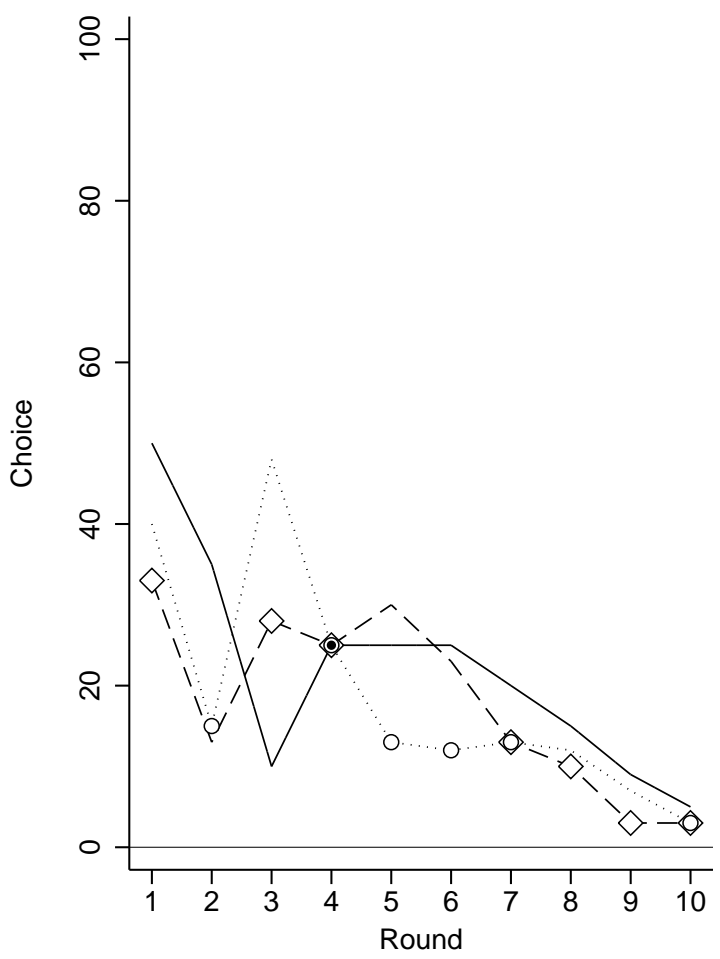

(a) Own-matched high ability group.

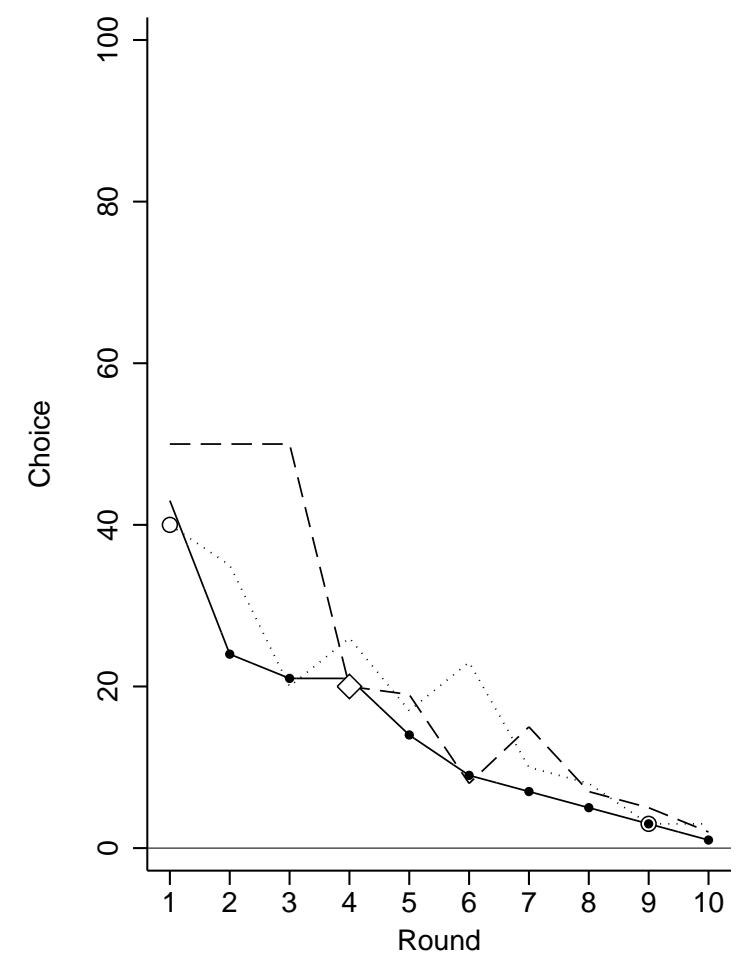

(c) Cross-matched group with 1 high ability subject.

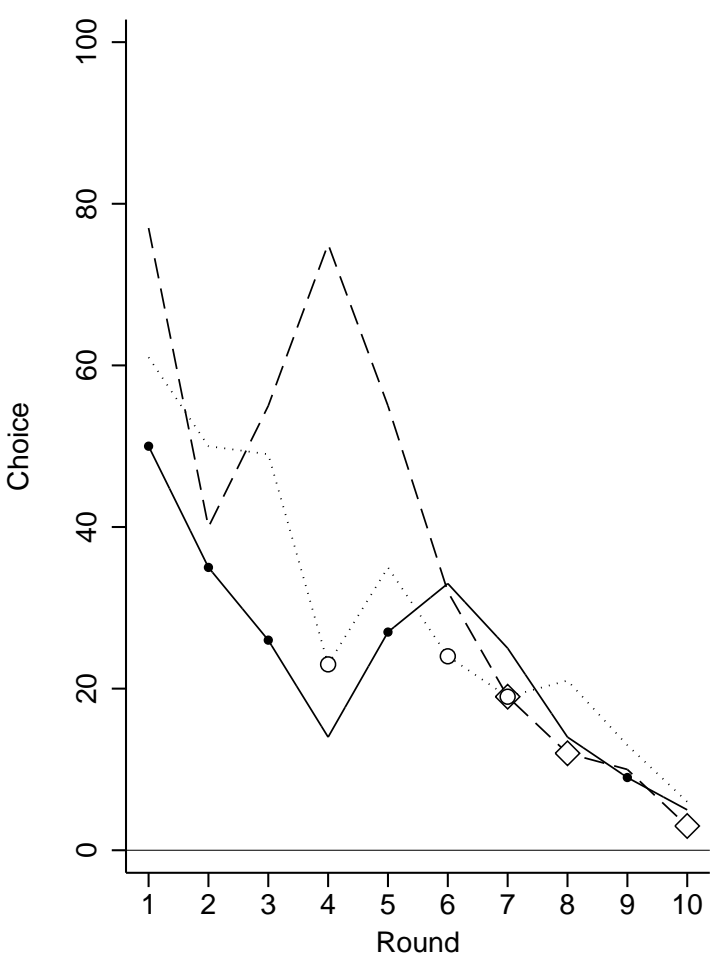

(b) Own-matched low ability group.

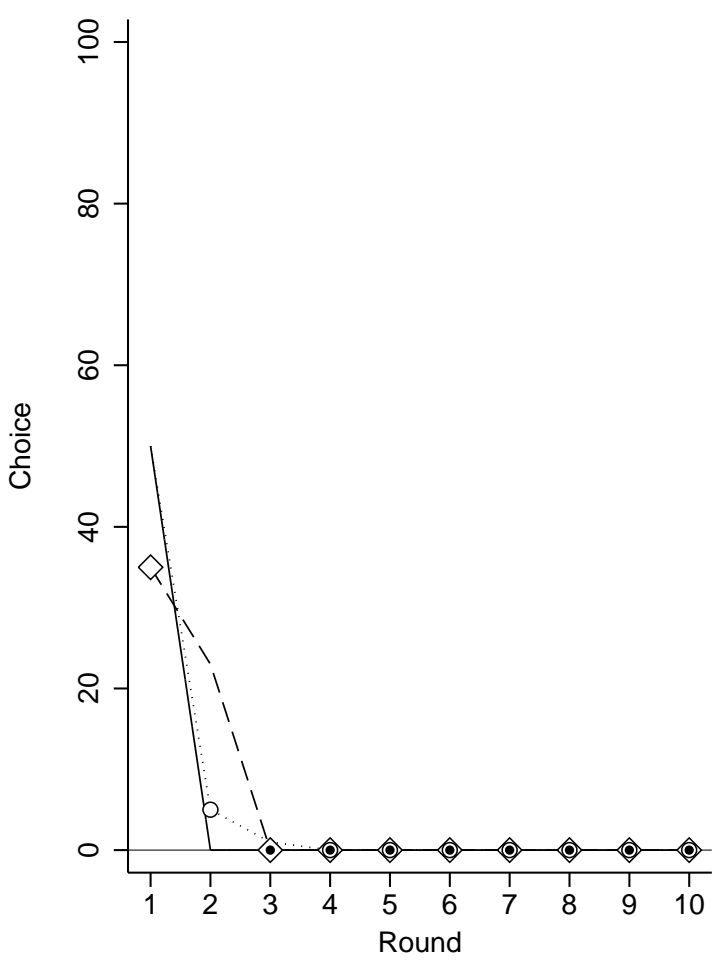

(d) Own-matched high ability group.

\begin{tabular}{|cl|}
\hline- & Winning choice of subject represented by solid line \\
$\circ$ & Winning choice of subject represented by dotted line \\
$\diamond$ & Winning choice of subject represented by dashed line \\
\hline
\end{tabular}

Notes: Ties are represented by overlapping markers. In cross-matched groups, the subject represented by the solid line is of the minority cognitive ability type.

Figure 5: Examples of group-by-group behavior: groups 1-4 of 8 . 

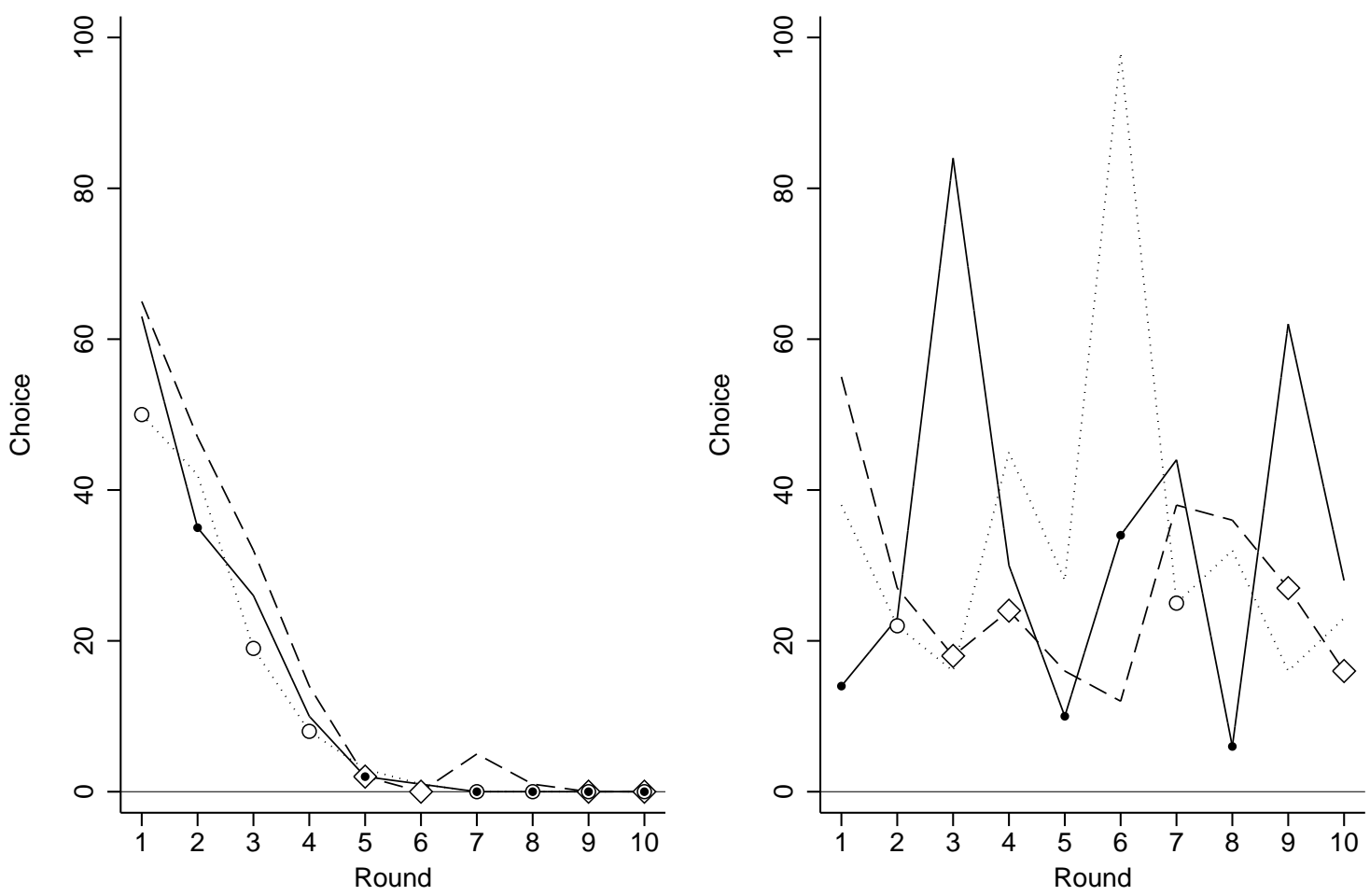

(a) Cross-matched group with 1 high ability subject. (b) Cross-matched group with 2 high ability subjects.

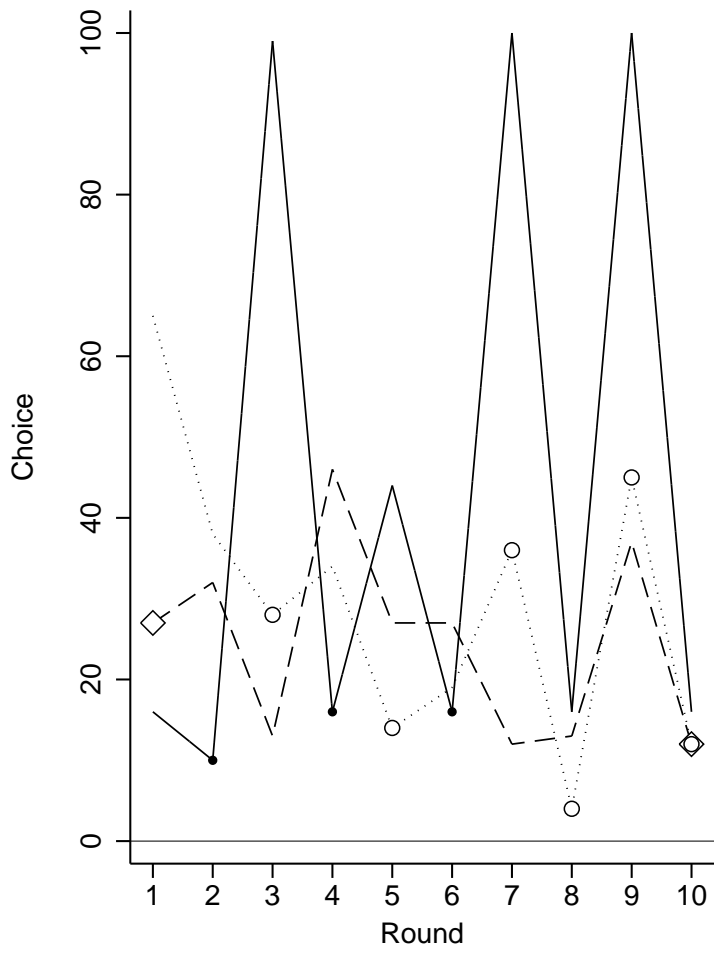

(c) Own-matched low ability group.

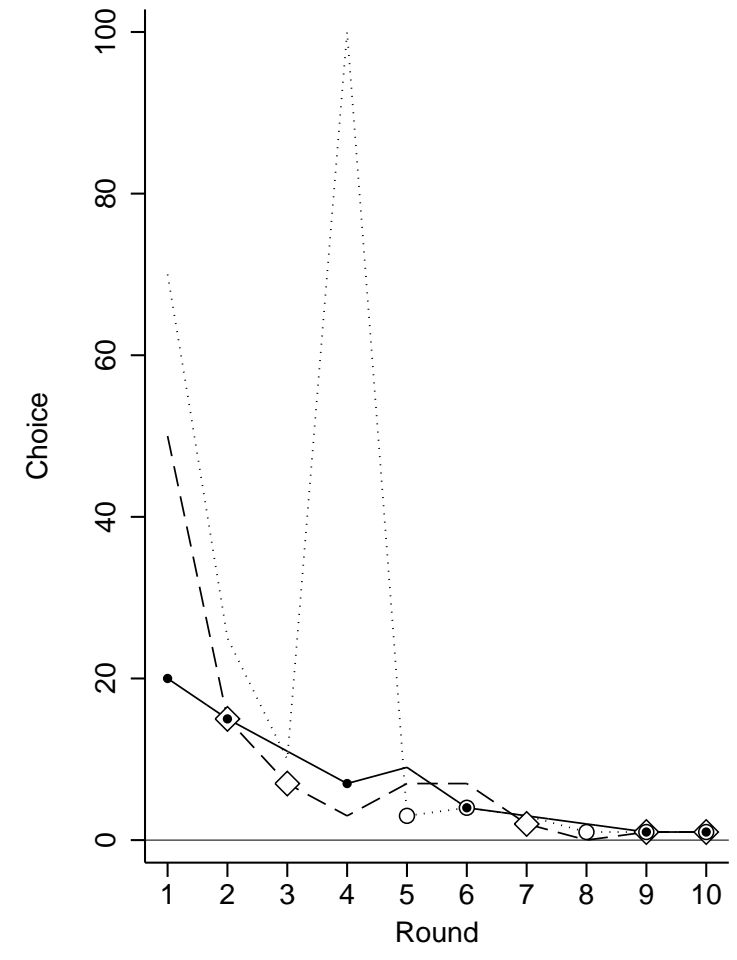

(d) Own-matched high ability group.

\begin{tabular}{|cl|}
\hline- & Winning choice of subject represented by solid line \\
$\circ$ & Winning choice of subject represented by dotted line \\
$\diamond$ & Winning choice of subject represented by dashed line \\
\hline
\end{tabular}

Notes: Ties are represented by overlapping markers. In cross-matched groups, the subject represented by the solid line is of the minority cognitive ability type.

Figure 6: Examples of group-by-group behavior: groups 5-8 of 8 . 
Figure 6(d) shows an own-matched high ability group in which such a high choice seems hardly to affect the learning process at all.

\subsubsection{Statistics on group-by-group convergence}

Of course, the figures in Section 4.3.1 illustrate the behavior of just a small subset of the 260 groups in our sample. We now study the degree of convergence more systematically, differentiating between own-matched high ability groups, cross-matched groups and own-matched low ability groups. Table 1 shows the frequency of equilibrium and close-to-equilibrium play in the final 2 rounds of the experiment.

Equilibrium $\quad$ Group mean $\leq 1 \quad$ Group mean $\leq 2$

\section{Observed proportions:}

$\begin{array}{cccc}\text { Own-matched high ability groups } & 0.293 & 0.453 & 0.540 \\ \text { Cross-matched groups } & 0.145 & 0.282 & 0.368 \\ \text { Own-matched low ability groups } & 0.127 & 0.247 & 0.313\end{array}$

Cross-group differences in proportions:

Own-matched high ability groups vs. own-matched low ability groups

\begin{tabular}{|c|c|c|}
\hline $\begin{array}{l}0.167^{* * *} \\
(0.062)\end{array}$ & $\begin{array}{l}0.207^{* * *} \\
(0.072)\end{array}$ & $\begin{array}{l}0.227^{* * *} \\
(0.072)\end{array}$ \\
\hline $\begin{array}{l}0.148^{* *} \\
(0.059)\end{array}$ & $\begin{array}{l}0.172^{* *} \\
(0.069)\end{array}$ & $\begin{array}{l}0.172^{* *} \\
(0.070)\end{array}$ \\
\hline $\begin{array}{l}0.019 \\
(0.049)\end{array}$ & $\begin{array}{l}0.035 \\
(0.061)\end{array}$ & $\begin{array}{l}0.055 \\
(0.064)\end{array}$ \\
\hline
\end{tabular}

Own-matched high ability groups vs. cross-matched groups

$(0.049)$

$(0.064)$

Notes: The table is based on 520 group-round observations (the 75 own-matched high ability groups, the 75 ownmatched low ability groups and the 110 cross-matched groups, observed in rounds 9 and 10). The first column reports the proportion of group-round observations in rounds 9 and 10 in which all 3 group members choose 0 . The second (third) column reports the proportion of group-round observations in rounds 9 and 10 in which the mean choice of the 3 group members is less than or equal to 1 (2). The statistical tests of differences in proportions are based on Ordinary Least Squares regressions. Heteroskedasticity-consistent standard errors (with clustering at the group level) are shown in parentheses. ${ }^{*},{ }^{* *}$ and ${ }^{* * *}$ denote significance at the $10 \%, 5 \%$ and $1 \%$ levels (2-sided tests).

Table 1: Proportions of equilibrium and close-to-equilibrium play in rounds 9 and 10.

The first column shows the proportion of equilibrium play, that is the proportion of groupround observations in which all 3 group members choose 0 . Own-matched high ability groups play the equilibrium around $29 \%$ of the time in the final 2 rounds, which is statistically significantly more often than for cross-matched groups (15\%) and own-matched low ability groups (13\%). The second and third columns show that the results extend when we consider close-toequilibrium play, defined to be the proportion of group-round observations in the final 2 rounds in which the mean choice of the 3 group members is less than or equal to 1 (second column) or 2 (third column). Own-matched high ability groups are close to equilibrium statistically significantly more frequently than cross-matched groups and own-matched low ability groups. 
In Section 5.3.1 we report how well our structural level- $k$ model of learning can match these differences in convergence according to group composition. In particular, we compare the observed proportions of equilibrium and close-to-equilibrium play to those arising from simulated choices constructed using the estimated parameters of the structural model, and we find that the structural model fits well the broad patterns that we find here.

\section{$5 \quad$ Structural analysis}

Section 4 presented a detailed reduced form description of how behavior and earnings vary with cognitive ability. To help gain insight into the behavioral mechanisms that underlie these differences we turn to a level- $k$ model of learning. Below we describe our empirical model's specification, our estimation strategy and our results.

\subsection{Level- $k$ model of learning}

We estimate a structural level- $k$ mixture-of-types model of learning using Maximum Likelihood. Choices in the first round serve as the initial conditions. Our level- $k$ model of learning includes nine learner types; and since our model includes rule learners, we distinguish level- $k$ types from level- $k$ choice rules (described below). Five fixed level- $k$ types with $k \in\{0,1,2,3,4\}$ follow the level- $k$ choice rule in all rounds $r \geq 2$ (therefore an individual drawn as a level- $k$ type follows the same choice rule in every round). We also include four rule learner types who switch from following the level- $k$ choice rule in round $r=2$, with $k \in\{0,1,2,3\}$, to following the level- $(k+1)$ choice rule in round $r=10$. For such $L k-(k+1)$ rule learners, the probability of choosing the level- $(k+1)$ choice rule increases linearly over rounds from 0 in round $r=2$ to 1 in round $r=10$ (and is thus given by $\frac{r-2}{8}$ in round $r$ ), while the complementary probability of choosing the level- $k$ choice rule falls linearly over rounds. ${ }^{21,22}$

Some further notation is necessary to describe the level- $k$ choice rules. Subject $i \in\{1,2,3\}$ in group $g \in\{1,2, \ldots, G\}$ is denoted by $i g \in\{1 g, 2 g, 3 g\}$. The choice of subject $i g$ in round $r \in\{1,2, \ldots, 10\}$ is denoted by $x_{i g, r} \in\{0,1, \ldots, 100\}$. The set of choices in round $r$ of the 3 subjects in group $g$ is denoted by $\mathbf{x}_{g, r} \equiv\left\{x_{1 g, r}, x_{2 g, r}, x_{3 g, r}\right\}$, with mean choice $\bar{x}_{g, r} \equiv\left(\sum_{i=1}^{3} x_{i g, r}\right) / 3$.

\footnotetext{
${ }^{21}$ Although the probability of choosing the level- $(k+1)$ choice rule goes up over time, a $L k-(k+1)$ rule learner is allowed to switch back and forth between the level- $k$ and level- $(k+1)$ choice rules. An alternative specification (AS1) in which rule learners make a once-and-for-all transition to the level- $(k+1)$ choice rule, and so cannot switch back, fits the data significantly less well (see Table 14 in Appendix B). Note also that in our mixture model framework, we do not model explicitly how rules are chosen; in contrast, Stahl (1996) uses an attraction framework in which a given rule is more attractive the higher its past payoff.

${ }^{22}$ We have successfully estimated richer and more parsimonious specifications of our level- $k$ model of learning. A Bayesian information criterion (BIC)-based model selection exercise selects the preferred specification over a richer model that additionally includes a fixed L5 type (that follows the L5 choice rule in every round $r \geq 2$ ) and a L4-5 rule learner type. Based on the same model selection criterion, the preferred specification also outperforms a more parsimonious model that excludes the fixed L4 type and the L3-4 rule learner type. Additionally, we estimated a specification that extends the preferred specification by including three 2-step rule learner types who switch from following the level- $k$ choice rule in round $r=2$, with $k \in\{0,1,2\}$, to following the level- $(k+2)$ choice rule in round $r=10$. The BIC values for the preferred specification and this extended specification are the same to 3 decimal places, and the estimates of the average level- $k$ choice rules followed by own-matched and cross-matched high and low cognitive ability subjects differ little between the two specifications (see Table 4 for the preferred specification estimates). However, due to the large number of similar types, we encountered numerical difficulties when trying to obtain standard errors for this extended specification; 2-step rule learners are therefore excluded from our analysis.
} 
To model the noise in the choice process, we assume that subjects' choices are independent draws (over rounds and subjects) from discretized and truncated $t$-distributions. ${ }^{23}$ Letting $f(\cdot ; \mu, \sigma, \nu)$ be the density of the three-parameter $t$-distribution with mean $\mu$, scale $\sigma$ and degrees of freedom $\nu$, the probability of a particular choice $x$ by subject $i g$ when following the level- $k$ choice rule in round $r \geq 2$ given the group-specific choices in the previous round $\mathbf{x}_{g, r-1}$ is

$$
\operatorname{Pr}\left(x \mid k, \mathbf{x}_{g, r-1}\right)=(1-\gamma(r)) \frac{f\left(x ; \mu\left(k, \mathbf{x}_{g, r-1}\right), \sigma(\mu, r), \nu\right)}{\sum_{x=0}^{99} f\left(x ; \mu\left(k, \mathbf{x}_{g, r-1}\right), \sigma(\mu, r), \nu\right)} \mathbf{1}_{x \in\{0,1, \ldots, 99\}}+\gamma(r) \mathbf{1}_{x=100}
$$

where $\mu\left(k, \mathbf{x}_{g, r-1}\right)=\left(\frac{7}{10}\right)^{k} \bar{x}_{g, r-1}$, rounded to the nearest integer, and $\gamma(r)$ is the probability of choosing 100 in round $r$ given by the empirical frequency of subjects choosing 100 that we observe in that round in our sample (independently of cognitive ability). ${ }^{24}$ Therefore, as in Nagel (1995), Stahl (1996) and Duffy and Nagel (1997), a subject following the level-0 choice rule "follows the crowd" in the sense that she aims to copy the average group behavior from the previous round, while a subject who follows the level- $k$ choice rule for $k>0$ best responds to level- $(k-1)$ choices in the sense that she aims to hit the current round's target in her group $t_{g, r} \equiv \frac{7}{10} \bar{x}_{g, r}$ that would result from everybody in the group noiselessly following the level- $(k-1)$ choice rule. $^{25}$

For all level- $k$ choice rules the scale parameter $\sigma$ depends on $\mu$ and on the round $r$ in the following way:

$$
\sigma(\mu, r)=\exp \left(\alpha+\left[\mathbf{1}_{\mu \in\{0\}}, \mathbf{1}_{\mu \in\{1\}}, \mathbf{1}_{\mu \in\{2,3,4,5\}}\right] \boldsymbol{\beta}-\delta\left(\frac{r-2}{8}\right)\right) .
$$

In the above, $\mathbf{1}_{\mu \in M}$ is an indicator function taking the value 1 when $\mu \in M$ and taking the value 0 otherwise, and $\boldsymbol{\beta}$ is a 3 -element vector. Thus we allow the variance of the discretized choice distribution to vary with $\mu$ in a flexible way and to include a round trend. ${ }^{26}$ The number of degrees of freedom $\nu$ is common to all level- $k$ choice rules.

\footnotetext{
${ }^{23}$ Stahl (1996) and Offerman et al. (2002) use truncated normal distributions to model noise in the choice process in structural models of learning. In Table 14 in Appendix B, we show that an alternative specification (AS2) in which the normal distribution replaces the $t$-distribution fits the data significantly less well.

${ }^{24}$ We observe 106 instances of subjects choosing 100 in our sample, making up $1.4 \%$ of observations. Although such extreme choices are a standard feature in beauty contest datasets, their attraction cannot be explained readily by level- $k$ choice rules. Ho et al. (1998) argue that such choices "are probably due to frustration or to misguided attempts to win by singlehandedly raising the mean dramatically." In Table 14 in Appendix B, we show that an alternative specification (AS3) in which the choices of 100 come from the same $t$-distribution as for the other choices fits the data significantly less well.

${ }^{25}$ If subjects took into account the effect of their own choice on the target, they would choose lower fractions of $\bar{x}_{g, r-1}$; however, in Table 14 in Appendix B, we show that an alternative specification (AS4) in which $\mu\left(k, \mathbf{x}_{g, r-1}\right)$ is given by this lower fraction fits the data significantly less well.

${ }^{26}$ We need the variance to depend on $\mu$ and $r$ in order to fit the degree of convergence towards equilibrium play that we observe in the data. The time trend is a function of $r-2$ since first round choices serve as the initial conditions and the second round acts as the omitted category. Stahl (1996) also allows the variance of the choice distribution to depend on $\mu$; Ho et al. (1998) allow a time trend in variances.
} 


\subsection{Estimation strategy}

Using the full sample of 780 subjects observed for 10 rounds, we estimate the parameter vector $\boldsymbol{\theta}$ that contains 38 elements. In more detail, we estimate the parameters that describe the probabilities of being the 9 different learner types for own-matched high cognitive ability subjects, cross-matched high ability subjects, cross-matched low ability subjects and own-matched low ability subjects, giving $8 \times 4=32$ parameters. In addition, we estimate the 6 parameters of the $t$-distribution ( $\alpha$, the 3-element vector $\boldsymbol{\beta}, \delta$ and $\nu$ ). Recall that our model includes fixed level- $k$ types who follow the same choice rule in every round and rule learners who switch choice rules over time. Letting $k_{i g, r}$ be the level- $k$ choice rule that subject $i g$ follows in round $r$, the set of level- $k$ choice rules followed by the 3 subjects in group $g$ in round $r$ is denoted by $\mathbf{k}_{g, r} \equiv\left\{k_{1 g, r}, k_{2 g, r}, k_{3 g, r}\right\}$, and the set of group $g^{\prime} s$ choice rules for every round $r \geq 2$ is denoted by $\mathbf{k}_{g} \equiv\left\{\mathbf{k}_{g, 2}, \mathbf{k}_{g, 3}, \ldots, \mathbf{k}_{g, 10}\right\}$. The 32 parameters that measure the probabilities of the different learner types determine the probability of each different combination of choice rules, so $\operatorname{Pr}\left(\mathbf{k}_{g}\right)$ depends on $\boldsymbol{\theta}$. Finally, letting $\mathbf{x}_{g} \equiv\left\{\mathbf{x}_{g, 2}, \mathbf{x}_{g, 3}, \ldots, \mathbf{x}_{g, 10}\right\}$ be the set of group $g^{\prime} s$ choices for every round $r \geq 2$,

$$
\operatorname{Pr}\left(\mathbf{x}_{g} \mid \mathbf{k}_{g}, \mathbf{x}_{g, 1}\right)=\prod_{r=2}^{10} \operatorname{Pr}\left(\mathbf{x}_{g, r} \mid \mathbf{k}_{g, r}, \mathbf{x}_{g, r-1}\right)=\prod_{r=2}^{10} \prod_{i=1}^{3} \operatorname{Pr}\left(x_{i g, r} \mid k_{i g, r}, \mathbf{x}_{g, r-1}\right),
$$

and the likelihood for group $g$

$$
L_{g}\left(\boldsymbol{\theta} \mid \mathbf{x}_{g}, \mathbf{x}_{g, 1}\right)=\operatorname{Pr}\left(\mathbf{x}_{g} \mid \mathbf{x}_{g, 1}\right)=\sum_{\mathbf{k}_{g}} \operatorname{Pr}\left(\mathbf{k}_{g}\right) \operatorname{Pr}\left(\mathbf{x}_{g} \mid \mathbf{k}_{g}, \mathbf{x}_{g, 1}\right) .
$$

The sample likelihood is then the product over the $G$ groups of the group likelihoods.

We maximized the sample log likelihood function using a Hessian-based optimization routine. Following Berndt et al. (1974), the Hessian employed in the optimization process was approximated as the sum of outer products of the gradients of the group log likelihoods. The gradients of the group log likelihoods, in turn, were obtained via numerical differentiation. Standard errors were obtained from a Hessian matrix computed using numerical differentiation. We found the optimization problem to be well behaved. In particular, the optimization routine converged to the same parameter vector for multiple sets of starting values, and the Hessian matrix used to obtain standard errors was never found to be close to singular. ${ }^{27}$

\subsection{Results}

In Section 5.3.1, we start by reporting the estimated proportions of learner types arising from our level- $k$ model of learning, and we provide evidence that our preferred specification fits well the differences in behavior by cognitive ability observed in the data. In Section 5.3.2, we then show how the subjects' average level- $k$ choice rule varies with their own cognitive ability and with that of their opponents. Finally, in Section 5.3.3 we simulate the earnings that accrue to different learner types in order to discover which learner types earn the most.

\footnotetext{
${ }^{27}$ According to the model outlined in Section 5.1, choice probabilities conditional on the group playing Nash equilibrium in the previous round are identical across learner types. However, there are enough group-round observations in which Nash equilibrium was not played to identify all the learner type probabilities.
} 


\subsubsection{Estimated learner types and model goodness of fit}

Table 2 reports the estimated proportions of learner types. ${ }^{28}$ In Section 5.3 .2 below we summarize this information in terms of average level- $k$ choice rules and analyze how the averages vary with own cognitive ability and that of opponents. Instead, our focus here is on the implications of these estimates for behavior in order to see how well our model fits the differences in behavior by cognitive ability in the observed data.

\begin{tabular}{|c|c|c|c|c|}
\hline & \multicolumn{2}{|c|}{ Own-matched subjects } & \multicolumn{2}{|c|}{ Cross-matched subjects } \\
\hline & High ability & Low ability & High ability & Low ability \\
\hline L0 Type & $\begin{array}{l}0.002 \\
(0.009)\end{array}$ & $\begin{array}{l}0.023^{*} \\
(0.016)\end{array}$ & $\begin{array}{l}0.004 \\
(0.009)\end{array}$ & $\begin{array}{l}0.021 \\
(0.018)\end{array}$ \\
\hline L1 Type & $\begin{array}{l}0.222^{* * *} \\
(0.045)\end{array}$ & $\begin{array}{l}0.280^{* * *} \\
(0.050)\end{array}$ & $\begin{array}{l}0.172^{* * *} \\
(0.052)\end{array}$ & $\begin{array}{l}0.409^{* * *} \\
(0.065)\end{array}$ \\
\hline L2 Type & $\begin{array}{l}0.148^{* * *} \\
(0.053)\end{array}$ & $\begin{array}{l}0.034 \\
(0.047)\end{array}$ & $\begin{array}{l}0.174^{* * *} \\
(0.067)\end{array}$ & $\begin{array}{l}0.281^{* * *} \\
(0.069)\end{array}$ \\
\hline L3 Type & 0.000 & 0.000 & $\begin{array}{l}0.053 \\
(0.051)\end{array}$ & 0.000 \\
\hline L4 Type & $\begin{array}{l}0.001 \\
(0.036)\end{array}$ & 0.000 & 0.000 & $\begin{array}{l}0.013 \\
(0.026)\end{array}$ \\
\hline L0-1 Rule learner type & $\begin{array}{l}0.043^{* *} \\
(0.025)\end{array}$ & $\begin{array}{l}0.113^{* * *} \\
(0.034)\end{array}$ & $\begin{array}{l}0.052^{* *} \\
(0.029)\end{array}$ & $\begin{array}{l}0.090^{* *} \\
(0.043)\end{array}$ \\
\hline L1-2 Rule learner type & $\begin{array}{l}0.218^{* * *} \\
(0.055)\end{array}$ & $\begin{array}{l}0.256^{* * *} \\
(0.057)\end{array}$ & $\begin{array}{l}0.334^{* * *} \\
(0.069)\end{array}$ & $\begin{array}{l}0.061 \\
(0.065)\end{array}$ \\
\hline L2-3 Rule learner type & $\begin{array}{l}0.177^{* * *} \\
(0.055)\end{array}$ & $\begin{array}{l}0.188^{* * *} \\
(0.051)\end{array}$ & $\begin{array}{l}0.186^{* * *} \\
(0.071)\end{array}$ & $\begin{array}{l}0.078^{*} \\
(0.061)\end{array}$ \\
\hline L3-4 Rule learner type & $\begin{array}{l}0.189^{* * *} \\
(0.058)\end{array}$ & $\begin{array}{l}0.106^{* * *} \\
(0.029)\end{array}$ & $\begin{array}{l}0.026 \\
(0.032)\end{array}$ & $\begin{array}{l}0.047 \\
(0.044)\end{array}$ \\
\hline Proportion of rule learners & $\begin{array}{l}0.627^{* * *} \\
(0.072)\end{array}$ & $\begin{array}{l}0.663^{* * *} \\
(0.070)\end{array}$ & $\begin{array}{l}0.597^{* * *} \\
(0.097)\end{array}$ & $\begin{array}{l}0.275^{\text {*** }} \\
(0.092)\end{array}$ \\
\hline
\end{tabular}

Notes: Standard errors are shown in parentheses. ${ }^{*},{ }^{* *}$ and ${ }^{* * *}$ denote significance at the $10 \%, 5 \%$ and $1 \%$ levels.

Table 2: Estimated learner type probabilities.

To give a visual impression of how well the model fits the observed data, we simulate choices over the 10 rounds using the estimated parameters. Figure 7 shows the simulated and observed paths of average behavior for own and cross-matched subjects: we see that the observed and simulated paths match closely (the notes to the figure explain how the simulated paths were constructed).

Figure 8 (a) shows the simulated path of earnings for cross-matched subjects (recall that, by construction, own-matched high ability subjects and own-matched low ability subjects must earn $\$ 2$ on average in every round). We fit the pattern of divergence in earnings over rounds, although the magnitude of the divergence is not quite as big as that observed in the data (see Figure 4(b) in Section 4.2.3). Our simulations return a divergence in earnings over rounds even though, as in the observed data, high and low ability cross-matched subjects' simulated choices

\footnotetext{
${ }^{28}$ The estimated parameters of the $t$-distribution, which complete the estimate of the parameter vector $\boldsymbol{\theta}$, are: $\alpha=-2.734(0.047) ; \boldsymbol{\beta}=[-2.778(0.102),-1.826(0.079),-1.134(0.066)] ; \delta=0.844(0.088) ;$ and $\nu=0.749(0.035)$. Standard errors are in parentheses. As reported in Table 14, the maximized log likelihood is $-21,510$.
} 

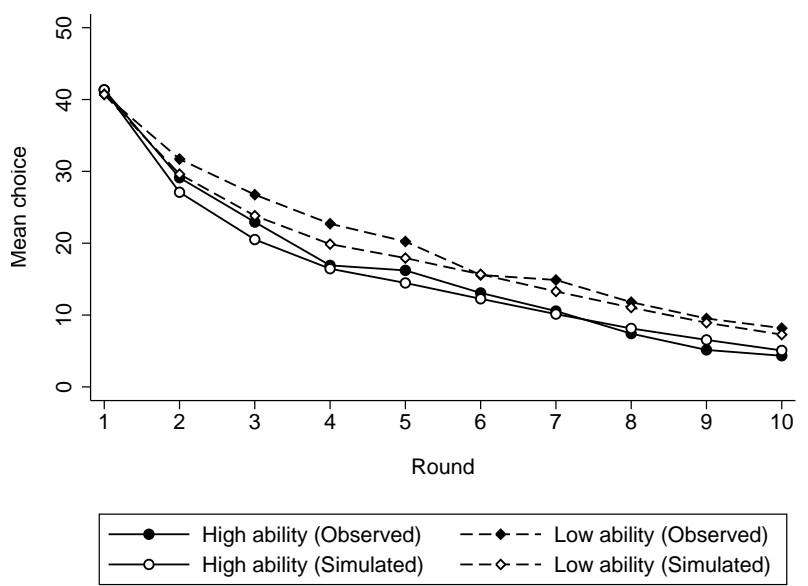

(a) Own-matched subjects.

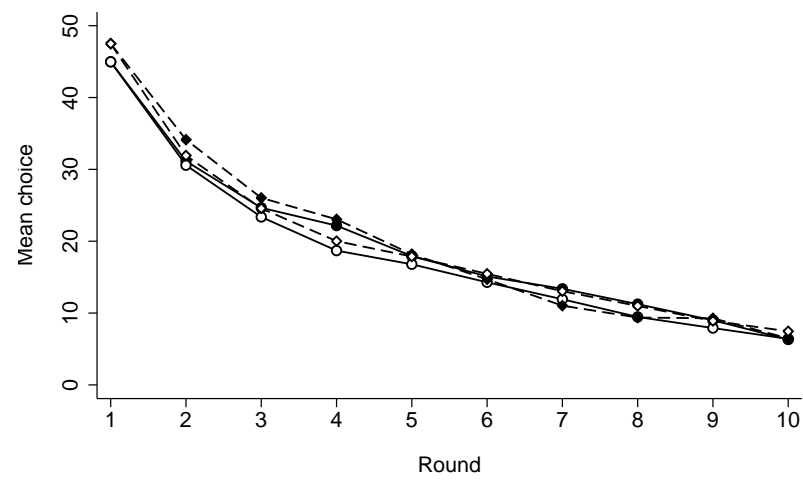

$\longrightarrow$ High ability (Observed) $\quad--\bullet--$ Low ability (Observed) $\longrightarrow$ High ability (Simulated) $\quad--\diamond--$ Low ability (Simulated)

(b) Cross-matched subjects.

Notes: Simulated choices were obtained using a sequential method. Specifically, for each of the 260 groups in the experimental sample we drew the type of each group member from the appropriate estimated distribution of learner types reported in Table 2. We then simulated the choice of each of the 3 group members in round 2 , given the observed behavior, specifically the group average, in the first round (in the figures, the simulated first round data are given by the observed data). Next, we simulated the choice of each of the 3 group members in round 3, given the average of the simulated choices of the group members in round 2. We continued sequentially in this manner to round 10, with simulated choices in each round being based on the group-level average of the simulated choices in the previous round. This procedure was repeated 100 times for each of the 260 groups.

Figure 7: Observed and simulated round-by-round means of choices.

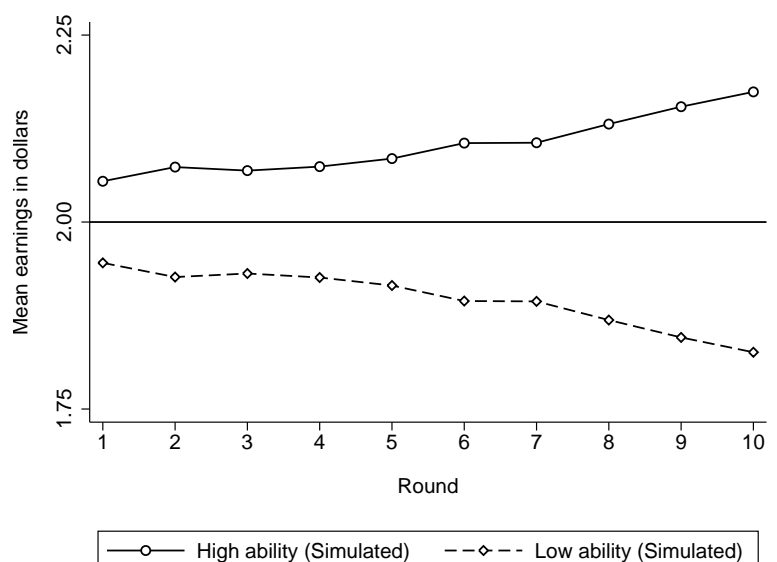

(a) Preferred specification.

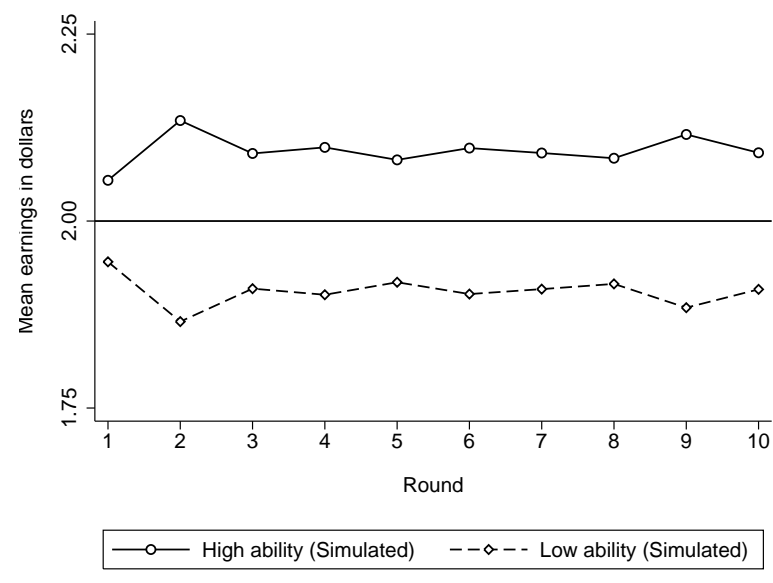

(b) Without rule learners.

Notes: Simulated earnings were computed from the simulated choices generated as described in the notes to Figure 7 .

Figure 8: Simulated round-by-round means of earnings of cross-matched subjects.

remain similar throughout the experiment. Rule learning is crucial to explaining the pattern of divergence: Table 2 shows that there are $60 \%$ of rule learners among cross-matched high ability subjects, but only $28 \%$ among cross-matched low ability subjects (the difference is statistically significant with a 2 -sided $p=0.016$ ), and Figure $8(\mathrm{~b})$ shows that when we re-estimate the model without rule learners we can no longer fit the divergence in earnings over rounds. Further evidence that rule learning plays an important role in explaining subjects' choices more generally comes from the estimates of an alternative specification of the structural model without rule 
learners: Table 14 in Appendix B shows that this alternative specification (AS5) fits the data significantly less well.

Table 3 shows that the simulated choices match the extent of equilibrium and close-toequilibrium play that we see in the data quite well. In particular, the simulated choices fit well the broad pattern of increasing convergence as the proportion of high ability subjects in the group goes up.

\begin{tabular}{cccc}
\hline \hline & Equilibrium & Group mean $\leq 1$ Group mean $\leq 2$ \\
\hline Own-matched high ability groups: & & & \\
Observed & 0.293 & 0.453 & 0.540 \\
Simulated & 0.201 & 0.357 & 0.471 \\
Cross-matched groups: & & & \\
Observed & 0.145 & 0.282 & 0.368 \\
Simulated & 0.109 & 0.228 & 0.336 \\
Own-matched low ability groups: & & & \\
Observed & 0.127 & 0.247 & 0.313 \\
Simulated & 0.107 & 0.218 & 0.317 \\
\hline
\end{tabular}

Notes: Simulated proportions were computed from the simulated choices generated as described in the notes to Figure 7 .

Table 3: Observed and simulated proportions of equilibrium and close-to-equilibrium play in rounds 9 and 10.

Appendix B provides further evidence that our structural level- $k$ model of learning fits well. In particular, Table 14 reports values of log likelihoods and of sums of squared deviations of choices, earnings and convergence statistics computed from simulated choices and provides evidence that our preferred specification fits better than various alternative specifications (some nested and others not), while Table 15 shows that our model continues to perform well out of sample.

\subsubsection{The impact of cognitive ability on average level- $k$ choice rules}

We now analyze how learner types vary with subjects' own cognitive ability and that of their opponents. To do this, we summarize the estimated proportions of learner types in a single statistic measuring the average level- $k$ choice rule followed by the subjects (the notes to Table 4 provide the details of how these averages of choice rules are computed). From Table 4, we can see that, across all rounds, the average level- $k$ choice rule followed by own-matched high ability subjects is 1.97, while for own-matched low ability subjects the average level is 1.63 , with the difference statistically significant at the $1 \%$ level. For cross-matched subjects, the difference is less pronounced but still evident: the average level followed by cross-matched high ability subjects is 1.76 , while for cross-matched low ability subjects the average level is 1.52 , with the difference significant at the $5 \%$ level. The average level followed by cross-matched high ability subjects is higher even though they face a lower number of high ability opponents on average than do cross-matched low ability subjects.

Thus subjects' own cognitive ability type has a significant effect on the average level that they follow: high cognitive ability subjects follow level- $k$ choice rules that are significantly higher on 
average than those followed by low ability subjects. Further evidence that cognitive ability plays an important role in determining subjects' choice rules comes from estimating an alternative specification of the structural model in which the probabilities of the different learner types are not allowed to vary with subjects' own cognitive ability or with whether subjects are in own-matched or cross-matched groups. Table 14 in Appendix B shows that this alternative specification (AS6) fits the data significantly less well.

\begin{tabular}{|c|c|c|c|c|c|c|}
\hline \multicolumn{3}{|c|}{ Own-matched subjects } & \multicolumn{3}{|c|}{ Cross-matched subjects } & \multirow{2}{*}{$\begin{array}{c}\text { Diff.- } \\
\text { in-Diff. }\end{array}$} \\
\hline High ability & Low ability & Diff. & High ability & Low ability & Diff. & \\
\hline $\begin{array}{l}1.974^{* * * *} \\
(0.074)\end{array}$ & $\begin{array}{l}1.629 * * * \\
(0.070)\end{array}$ & $\begin{array}{l}0.346^{* * *} \\
(0.101)\end{array}$ & $\begin{array}{l}1.759 * * * \\
(0.067)\end{array}$ & $\begin{array}{l}1.520^{* * *} \\
(0.077)\end{array}$ & $\begin{array}{l}0.240^{* *} \\
(0.102)\end{array}$ & $\begin{array}{l}0.106 \\
(0.144)\end{array}$ \\
\hline \multicolumn{3}{|c|}{ High ability subjects } & \multicolumn{3}{|c|}{ Low ability subjects } & Diff.- \\
\hline Own-matches & Cross-matche & Diff. & Cross-matchec & Own-matched & Diff. & in-Diff. \\
\hline$\underbrace{1.974^{* * *}}_{(0.074)}$ & $\begin{array}{l}1.759^{* * * *} \\
(0.067)\end{array}$ & $\begin{array}{l}0.215^{* *} \\
(0.099)\end{array}$ & $\begin{array}{l}1.520^{* * *} \\
(0.077)\end{array}$ & $\begin{array}{l}1.629^{* * *} \\
(0.070)\end{array}$ & $\begin{array}{r}-0.109 \\
(0.104)\end{array}$ & $\begin{array}{l}0.324^{* *} \\
(0.144)\end{array}$ \\
\hline
\end{tabular}

Notes: The average choice rule of an L $k$ type is $k$, as this type follows the level- $k$ choice rule in every round. The average choice rule of an $L k-(k+1)$ rule learner is $k+\frac{1}{2}$. We use the estimated proportions of learner types from Table 2 to compute the average level- $k$ choice rule over all learner types. Tests for the significance of differences and of differences-in-differences are 2-sided. Standard errors are shown in parentheses. ${ }^{*},{ }^{* *}$ and ${ }^{* * *}$ denote significance at the $10 \%, 5 \%$ and $1 \%$ levels.

Table 4: Estimated averages of level- $k$ choice rules.

We also find significant differences in how average level- $k$ choice rules respond to the cognitive ability of opponents. We noted in Section 3.2 that, on average, high ability subjects face $4 / 3$ more high ability opponents in own-matched groups than in cross-matched groups, while low ability subjects face $4 / 3$ more high ability opponents in cross-matched groups than in ownmatched groups. The second row of Table 4 shows that high cognitive ability subjects respond to the cognitive ability of their opponents: across all rounds, the average level followed by ownmatched high cognitive ability subjects is 0.21 higher than that followed by cross-matched high ability subjects, with the difference significant at the $5 \%$ level. Low cognitive ability subjects, on the other hand, do not respond to the cognitive ability of their opponents: the average level followed by cross-matched low ability subjects is not statistically significantly different from that followed by own-matched low ability subjects $(2$-sided $p=0.295)$. Furthermore, Table 4 shows that the difference-in-differences in how the average levels followed by high and low cognitive ability subjects respond to the cognitive ability of opponents is statistically significant (a 2-sided test shows significance at the $5 \%$ level).

Thus subjects' own cognitive ability has a significant effect on how the average level that they follow responds to the cognitive ability of their opponents: the average level- $k$ choice rule followed by high cognitive ability subjects responds significantly to the number of high ability opponents that they face, while the average level followed by low cognitive ability subjects does not respond. Further evidence that cognitive ability plays a role in determining how subjects' choice rules respond to the cognitive ability of opponents comes from estimating an alternative 
specification of the structural model in which the probabilities of the different learner types are not allowed to vary with whether subjects are in own-matched or cross-matched groups (but are allowed to vary with subjects' own cognitive ability). Table 14 in Appendix B provides evidence that this alternative specification (AS7) fits the data less well. ${ }^{29}$

\subsubsection{Levels and earnings}

Finally, we turn to the question of which learner types earn the most. The estimates of the structural model's parameters also allow us to simulate the earnings of each learner type, according to subjects' own cognitive ability and that of their opponents. Table 5 shows how simulated total earnings over rounds 2-10 vary according to learner type (the notes to the table describe how the simulated earnings were computed). The differences in earnings by learner type are large: for instance, L2 types earn about $40 \%$ more than L1 types across the board. In every case, the 3 best-performing learner types are L3 types, L4 types and L3-4 rule learners, although the order varies. This means that it is always optimal to be a high-level learner type, even for subjects facing a large proportion of low ability opponents who tend to choose higher numbers. In order of decreasing earnings, the order among the other 6 types is always: L2-3 rule learners; L2 types; L1-2 rule learners; L1 types; L1-0 rule learners; and finally L0 types.

\begin{tabular}{cccccc}
\hline \hline & \multicolumn{2}{c}{ Own-matched subjects } & & \multicolumn{2}{c}{ Cross-matched subjects } \\
\cline { 2 - 3 } \cline { 5 - 6 } & High ability & Low ability & & High ability & Low ability \\
\hline L0 Type & 7.83 & 8.41 & 8.69 & 8.25 \\
L1 Type & 14.00 & 15.22 & & 14.75 & 14.22 \\
L2 Type & 19.14 & 21.03 & & 21.22 & 20.70 \\
L3 Type & 21.96 & 23.53 & & 24.27 & 23.85 \\
L4 Type & $22.59^{\dagger}$ & 23.18 & & 23.42 & $24.03^{\dagger}$ \\
L0-1 Rule learner type & 10.35 & 11.49 & & 11.96 & 10.89 \\
L1-2 Rule learner type & 16.22 & 18.44 & & 18.42 & 17.35 \\
L2-3 Rule learner type & 21.35 & 22.31 & & 22.90 & 21.68 \\
L3-4 Rule learner type & 22.50 & $23.75^{\dagger}$ & $24.33^{\dagger}$ & 23.86 \\
\hline
\end{tabular}

Notes: ${ }^{\dagger}$ denotes the learner type that maximizes earnings according to subjects' own cognitive ability and that of their opponents. The earnings of a player of a particular learner type were computed based on simulated choices constructed using a method similar to that described in the notes to Figure 7 in which opponents' types were drawn from the appropriate estimated distribution of learner types from Table 2.

Table 5: Simulated total earnings over rounds 2-10 (in dollars) by learner type.

Given the estimated proportions of learner types reported in Table 2 and the average level- $k$ choice rules that subjects follow reported in Table 4, it is clear that subjects are constrained in their levels below those that are optimal, given the learner types of their opponents. Of course, unless subjects all play equilibrium, their level- $k$ choice rules will tend to be too low on average; nonetheless, subjects are leaving a substantial amount of money on the table.

\footnotetext{
${ }^{29}$ In our experiment, subjects can condition current behavior on: (i) information about the cognitive ability type composition of the group; and (ii) the previous behavior of the group members. Our design therefore allows us to identify how group composition affects current behavior conditional on past group behavior. Our design does not allow us to identify how subjects would respond to a given history if they did not know the group composition.
} 
On average own-matched high ability subjects earn $\$ 18$ across rounds $2-10$, and so are leaving $\$ 4.59$ on the table compared to the payoff-maximizing L4 type (recall from Table 4 that the average level- $k$ choice rule followed by these subjects is only 1.97). Own-matched low ability subjects also earn $\$ 18$ on average, and so are leaving $\$ 5.75$ on the table compared to the payoffmaximizing L3-4 rule learner type (from Table 4, their average level is 1.63). Thus, even though high and low ability own-matched subjects earn the same amount on average by construction, low ability subjects leave more money on the table.

Cross-matched high ability subjects earn $\$ 19.73$ across rounds 2 -10, and so are leaving $\$ 4.61$ on the table compared to the payoff-maximizing L3-4 rule learner type (their average level is 1.76). Cross-matched low ability subjects earn $\$ 16.27$ on average, and so are leaving $\$ 7.75$ on the table compared to the payoff-maximizing L4 type (their average level is just 1.52). L1 types are the most common among cross-matched low ability subjects, making up $41 \%$ of the total: they earn a striking $\$ 9.80$ less on average than the payoff-maximizing learner type.

Finally, by not adjusting their level upward on average, the low cognitive ability subjects lose out relative to the payoff-maximizing type when the cognitive ability of their opponents goes up: the low ability subjects leave $\$ 2.01$ more on the table in cross-matched groups than in own-matched low ability groups (from above, $\$ 7.75$ minus $\$ 5.75$ ). In contrast, the high ability subjects adjust their level upward and do not lose out: the high ability subjects leave the same amount of money on the table in own-matched high ability groups and in cross-matched groups (from above, $\$ 4.59$ and $\$ 4.61$ ).

\section{Comparing the effects of cognitive ability and character skills}

As well as exploring how cognitive ability influences behavior, success and the evolution of play towards Nash equilibrium in repeated strategic interactions, we are also interested in discovering the effects of character skills. To this end, we administered questionnaires to measure character skills of a subset of our subjects. Section 6.1 describes our measures of character skills, Section 6.2 presents a reduced form analysis comparing the behavioral effects of cognitive ability and character skills, while Section 6.3 builds on our structural level- $k$ model of learning to compare the influence of cognitive ability and character skills on the level- $k$ choice rules followed by our subjects.

\subsection{Measuring character skills}

As noted in Section 3.1, a subset of our sessions included questionnaires to measure character skills that were administered before the test of cognitive ability. We ran these 15 sessions in January 2014, with 18 subjects in each session and 270 participants in total. Apart from administering the questionnaires, these sessions were run in the manner described in Section 3. All the sessions were 'own-matched', giving 45 groups of 3 own-matched high cognitive ability subjects and 45 groups of 3 own-matched low cognitive ability subjects.

We measured 7 character skills: openness, conscientiousness, extraversion, agreeableness and emotional stability (the Big Five), grit and Consideration of Future of Consequences (CFC). We measured the Big Five using the 44-item Big Five Inventory (John et al., 1991; John et al., 
2008), grit using the 12-item Grit Scale (Duckworth et al., 2007), and CFC using the 12-item CFC Scale (Strathman et al., 1994), in that order. ${ }^{30}$ These three questionnaires use a 5 -point Likert scale to measure responses to individual questions. ${ }^{31}$ We gave the subjects 8 minutes to complete the 68 questions, which were displayed on 17 screens. ${ }^{32}$ The subjects could move back and forth between the 17 screens and, time permitting, they were allowed to change their previous answers. We did not provide any monetary incentives for answering the questions. The experimental instructions provided are in the Supplementary Web Appendix.

Table 6 presents the correlation matrix for our 7 measures of character skills. Many of the correlations are high. For instance, we find a correlation of 0.63 between conscientiousness and grit, of 0.39 between grit and CFC, of 0.38 between conscientiousness and CFC, and of 0.34 between agreeableness and emotional stability. A further 5 correlations are above $0.2 .{ }^{33}$

\begin{tabular}{lrcccccr}
\hline \hline \multicolumn{1}{c}{ Character skill } & $\mathrm{O}$ & $\mathrm{C}$ & $\mathrm{E}$ & $\mathrm{A}$ & $\mathrm{ES}$ & $\mathrm{G}$ & $\mathrm{CFC}$ \\
\hline Openness & 1.000 & & & & & & \\
Conscientiousness & -0.045 & 1.000 & & & & & \\
Extraversion & 0.130 & 0.111 & 1.000 & & & & \\
Agreeableness & 0.097 & 0.211 & 0.112 & 1.000 & & & \\
Emotional stability & 0.024 & 0.230 & 0.181 & 0.341 & 1.000 & & \\
Grit & -0.041 & 0.629 & 0.242 & 0.183 & 0.275 & 1.000 & \\
Consideration of Future Consequences & 0.246 & 0.381 & 0.174 & 0.041 & 0.085 & 0.388 & 1.000 \\
\hline
\end{tabular}

Table 6: Correlations between measures of character skills.

The high degree of correlation between our 7 measures of character skills justifies the construction of a smaller number of uncorrelated factors to identify the effects of character skills on behavior and compare the effects to that of cognitive ability. We undertake a principal component factor analysis with Varimax rotation, implemented to give factors that are uncorrelated with each other (see Jolliffe, 1995). Pre-rotation, 3 factors have eigenvalues above 1, and so these are retained in the rotation. ${ }^{34}$ These 3 factors explain $66 \%$ of the variance (Factor 1 explains $28 \%$, Factor 2 explains a further $20 \%$ and Factor 3 explains the final $18 \%$ ). The factors have zero mean and unit variance by construction.

\footnotetext{
${ }^{30}$ John et al. (2008) provide a detailed description and history of the Big Five. Borghans et al. (2008, p. 1008), argue that it is more helpful to use the term emotional stability rather than its obverse, neuroticism. Grit is defined as "perseverance and passion for long-term goals" (Duckworth et al., 2007, p. 1087) and is viewed as a measure of persistence (Borghans et al., 2011, p. 318). CFC is a survey-based measure of time preference: in particular, CFC is designed to measure "a stable individual difference in the extent to which people consider distant versus immediate consequences of potential behaviors" (Strathman et al., 1994, p. 742). Houser and Winter (2004) and Daly et al. (2009) find a statistically significant correlation between CFC and discount rates measured using incentivized choice tasks. Recent papers have found a relationship between CFC and behaviors such as savings (Webley and Nyhus, 2013), study habits (Delaney et al., 2013) and willingness to undertake training (Fouarge et al., 2013), while Strathman et al. (1994) find a relationship with concern for health, alcohol consumption, smoking and environmentally-friendly behavior.

${ }^{31} 0.3 \%$ of the responses are missing $(57$ of $270 \times 68=18,360)$. For each question, we replaced any missing responses by the sample average of the non-missing responses to that particular question.

${ }^{32}$ The Big Five Inventory alone is designed to take about 5 minutes (John et al., 2008, p. 137).

${ }^{33}$ The correlations between grit and the Big Five are similar to those found by Duckworth et al. (2007): $r=0.77$ (Study 2) and $r=0.64$ (Study 5) for conscientiousness; $r=0.38$ for emotional stability; $r=0.24$ for agreeableness; $r=0.22$ for extraversion; and $r=0.14$ for openness. Strathman et al. (1994) find a correlation of 0.49 between CFC and conscientiousness (they did not measure the other Big Five traits).

${ }^{34}$ Retaining factors with eigenvalues above 1 is a standard criterion for choosing the number of factors due to Kaiser (1960).
} 
Table 7 presents the factor loadings. As we can see from the table, Factor 1 mainly captures conscientiousness, grit and CFC, Factor 2 mainly captures agreeableness and emotional stability, while Factor 3 mainly captures openness, extraversion and CFC. The correlations between cognitive ability and these factors are low and are reported in the fifth paragraph of Section 6.2.2.

\begin{tabular}{lccc}
\hline \hline \multicolumn{1}{c}{ Character skill } & Factor 1 & Factor 2 & Factor 3 \\
\hline Openness & -0.085 & 0.043 & 0.886 \\
Conscientiousness & 0.845 & 0.156 & -0.108 \\
Extraversion & 0.221 & 0.295 & 0.440 \\
Agreeableness & 0.067 & 0.797 & 0.070 \\
Emotional stability & 0.199 & 0.770 & -0.009 \\
Grit & 0.850 & 0.195 & -0.041 \\
Consideration of Future Consequences & 0.668 & -0.162 & 0.483 \\
\hline
\end{tabular}

Table 7: Factor loadings.

\subsection{Reduced form comparison of cognitive ability and character skills}

In this section, we compare the behavioral effects of cognitive ability and character skills. In Section 6.2.1, we first describe the influence of character skills on round-by-round choices. In Section 6.2.2, we compare the effects of cognitive ability and character skills on average choices and earnings. Finally, in Section 6.2.3, we examine the influence of cognitive ability and character skills on learning at the group level.

\subsubsection{Round-by-round choices according to character skills}

We start by providing a visual description of how the 3 factors capturing character skills influence behavior in the $p$-beauty contest. Figure 9 shows the round-by-round evolution of mean choices for subjects categorized as high (above the sample median) or low (below the sample median) on Factor 1 and Factor 3. Across all 10 rounds, the mean choice of high Factor 1 subjects is not statistically significantly different from that of low Factor 1 subjects $(2$-sided $p=0.608)$, and the same is true for Factor $3(2$-sided $p=0.862) .{ }^{35}$

However, as illustrated in Figure 10, across the 10 rounds the mean choice of subjects high on Factor 2 is 2.7 lower than that of subjects low on Factor 2, and the difference is highly statistically significant (2-sided $p=0.010)$. By the final round, the mean choice of high Factor 2 subjects falls to 4.9, while that of low Factor 2 subjects falls to 8.1, and the difference of 3.3 is also statistically significant (2-sided $p=0.033)$. Thus, subjects high on Factor 2 , who are more agreeable and emotionally stable, tend to choose numbers closer to equilibrium, both on average across the 10 rounds and in the final round after a period of learning.

\footnotetext{
${ }^{35}$ The statistical tests in Section 6.2 .1 are based on Ordinary Least Squares regressions, and use heteroskedasticity-consistent standard errors with clustering at the group level. The regressions use the 270 subjects whose character skills we measured, observed for 10 rounds or, in the last case, just in round 10.
} 

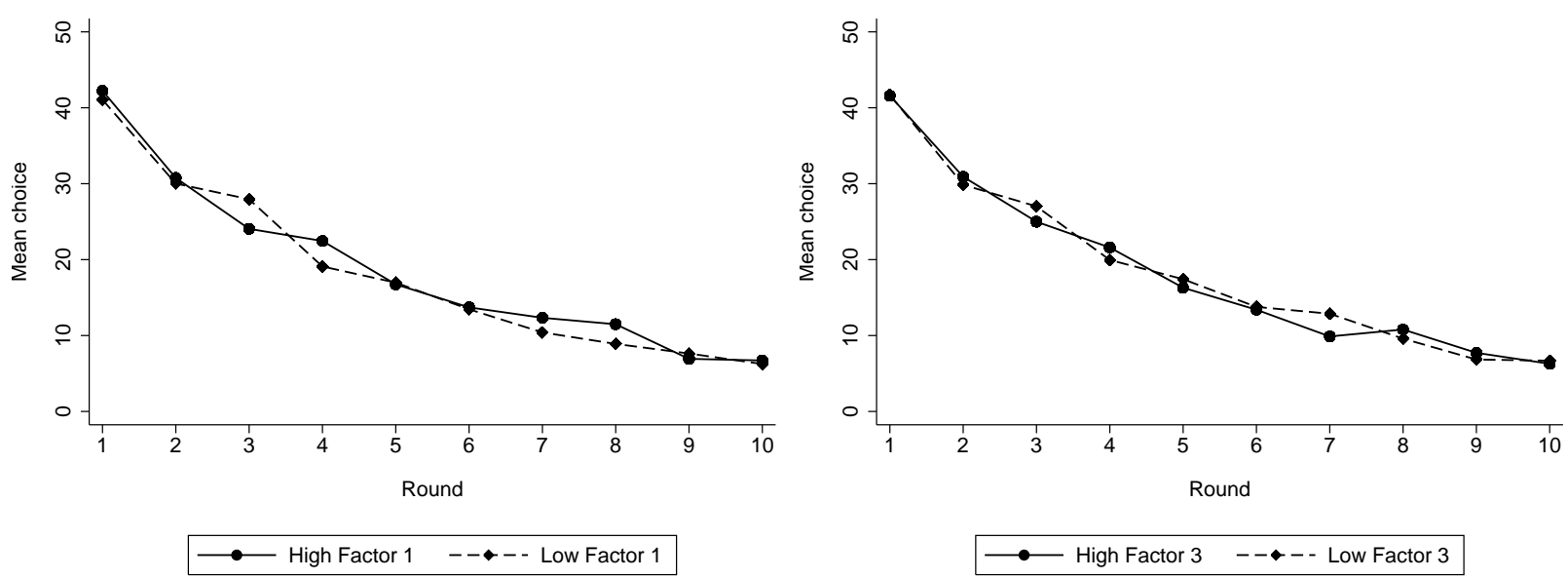

Figure 9: Round-by-round means of p-beauty contest choices: Factor 1 and Factor 3.

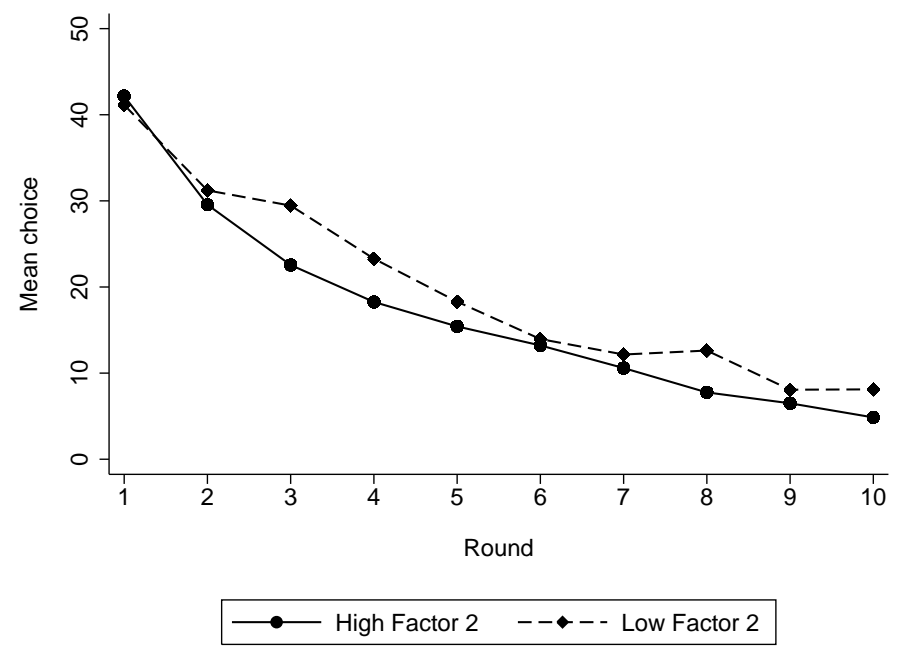

Figure 10: Round-by-round means of $p$-beauty contest choices: Factor 2.

\subsubsection{Comparison of the effects on average choices and earnings}

Next, we compare the effects of cognitive ability and character skills on choices and earnings across the 10 rounds. We run linear regressions of choices and earnings on subjects' score in the Raven test and on the three factors that capture character skills. Recall that we matched subjects by cognitive ability type but not according to their character skills. Thus, these regressions measure the effects of cognitive ability and character skills within matching group: that is, they measure the effects of cognitive ability and character skills within the set of subjects who were matched into groups of 3 high cognitive ability subjects and within the set of subjects who were matched into groups of 3 low cognitive ability subjects. Since the factors have zero mean and unit variance by construction, we standardize the Raven test scores to also have zero mean and unit variance.

Table 8 reports the results of the regressions of average choices on cognitive ability and character skills. The top panel reports the results of regressions that use all 270 subjects whose character skills we measured, while the other panels report the results of regressions that use only the 135 own-matched high cognitive ability subjects (middle panel) and the 135 own-matched 
low ability subjects (bottom panel). In each case, model (1) includes only cognitive ability as an explanatory variable, model (2) includes only character skills, and model (3) includes both cognitive ability and character skills.

Looking first at model (3) in the top panel of Table 8, we see that both cognitive ability and character skills influence behavior. In particular, a 1 standard deviation increase in the Raven test score reduces subjects' mean choice across the 10 rounds by 2.2 , while a 1 standard deviation increase in Factor 2, which captures an increase in agreeableness and emotional stability, reduces choices by 1.2 . These reductions represent decreases of $12 \%$ and $7 \%$, respectively, in choices relative to the mean. Factors 1 and 3 do not have a statistically significant effect on behavior. Thus, the impact of cognitive ability on behavior is about $75 \%$ bigger than that of character skills, which operates through Factor 2.

Second, looking at model (3) in the middle and bottom panels of Table 8, we see that the effect of increasing cognitive ability on behavior operates mainly through the subjects who are already high in cognitive ability, while character skills affect the behavior of both high and low cognitive ability subjects. Within the subjects already high in cognitive ability, a 1 standard deviation increase in the Raven test score reduces subjects' mean choice by 4.0, a reduction of $22 \%$ relative to the mean.

Third, comparing the estimates across models (1)-(3), we see that the estimated influence of cognitive ability on behavior does not depend on whether we control for character skills, and vice versa. Consistent with this, our measures of cognitive ability and character skills are not strongly correlated: we find a correlation of -0.14 between cognitive ability and Factor 1 , of 0.07 between cognitive ability and Factor 2 , and of 0.01 between cognitive ability and Factor $3 .{ }^{36}$

In summary, Table 8 shows that: (i) both cognitive ability and character skills influence behavior in our repeated strategic interaction; (ii) subjects higher in cognitive ability and higher in Factor 2 (which captures agreeableness and emotional stability) choose numbers closer to equilibrium; (iii) changes in cognitive ability have a more powerful effect on behavior than changes in character skills; (iv) marginal changes in cognitive ability mainly affect the behavior of subjects who are already cognitively able, while changes in character skills influence the behavior of subjects who are high or low in cognitive ability; and (v) the estimated influence of cognitive ability does not depend on whether we control for character skills, and vice versa.

\footnotetext{
${ }^{36}$ As noted by Almlund et al. (2011), most character skills are weakly correlated with cognitive ability (p. 46), particularly so for measures of fluid intelligence (p. 43), but character skills may nonetheless have some influence on measured cognitive ability (Section 5.6).
} 


\begin{tabular}{|c|c|c|c|}
\hline \multicolumn{4}{|c|}{ All subjects } \\
\hline & $(1)$ & $(2)$ & $(3)$ \\
\hline Standardized Raven test score & $\begin{array}{c}-2.142^{* *} \\
(0.971)\end{array}$ & & $\begin{array}{c}-2.177^{* *} \\
(0.985)\end{array}$ \\
\hline Factor 1 & & $\begin{array}{l}0.360 \\
(0.517)\end{array}$ & $\begin{array}{l}0.153 \\
(0.530)\end{array}$ \\
\hline Factor 2 & & $\begin{array}{c}-1.282^{* *} \\
(0.508)\end{array}$ & $\begin{array}{c}-1.238^{* *} \\
(0.484)\end{array}$ \\
\hline Factor 3 & & $\begin{array}{l}0.384 \\
(0.604)\end{array}$ & $\begin{array}{l}0.411 \\
(0.585)\end{array}$ \\
\hline Subject-round observations & 2,700 & 2,700 & 2,700 \\
\hline \multicolumn{4}{|c|}{ Own-matched high cognitive ability subjects } \\
\hline & $(1)$ & $(2)$ & $(3)$ \\
\hline Standardized Raven test score & $\begin{array}{c}-3.935^{* * *} \\
(1.018)\end{array}$ & & $\begin{array}{c}-4.029^{* * *} \\
(1.024)\end{array}$ \\
\hline Factor 1 & & $\begin{array}{l}0.111 \\
(0.475)\end{array}$ & $\begin{array}{r}-0.347 \\
(0.522)\end{array}$ \\
\hline Factor 2 & & $\begin{array}{c}-1.049^{*} \\
(0.618)\end{array}$ & $\begin{array}{c}-1.082^{*} \\
(0.587)\end{array}$ \\
\hline Factor 3 & & $\begin{array}{l}0.219 \\
(0.767)\end{array}$ & $\begin{array}{l}0.309 \\
(0.767)\end{array}$ \\
\hline Subject-round observations & 1,350 & 1,350 & 1,350 \\
\hline \multicolumn{4}{|c|}{ Own-matched low cognitive ability subjects } \\
\hline & $(1)$ & $(2)$ & $(3)$ \\
\hline Standardized Raven test score & $\begin{array}{r}-0.556 \\
(1.555)\end{array}$ & & $\begin{array}{r}-0.636 \\
(1.541)\end{array}$ \\
\hline Factor 1 & & $\begin{array}{l}0.522 \\
(0.905)\end{array}$ & $\begin{array}{l}0.509 \\
(0.899)\end{array}$ \\
\hline Factor 2 & & $\begin{array}{c}-1.353^{*} \\
(0.740)\end{array}$ & $\begin{array}{c}-1.372^{*} \\
(0.747)\end{array}$ \\
\hline Factor 3 & & $\begin{array}{l}0.552 \\
(0.899)\end{array}$ & $\begin{array}{l}0.559 \\
(0.886)\end{array}$ \\
\hline Subject-round observations & 1,350 & 1,350 & 1,350 \\
\hline
\end{tabular}

Notes: The models are linear and estimated using Ordinary Least Squares regressions. The regressions in the top panel use the 270 subjects whose character skills we measured, observed for 10 rounds. For all regressions, we standardize the Raven test scores using these 270 subjects. All models include an intercept. In the top panel, models (1) and (3) include a dummy for whether subjects are own-matched high cognitive ability or ownmatched low cognitive ability (the coefficients on the dummy are not statistically significantly different from 0 ). Heteroskedasticity-consistent standard errors with clustering at the group level are shown in parentheses. ${ }^{*},{ }^{* *}$ and $^{* * *}$ denote significance at the $10 \%, 5 \%$ and $1 \%$ levels (2-sided tests).

Table 8: Effects of cognitive ability and character skills on mean $p$-beauty contest choices. 
Table 9 shows that the effects of cognitive ability and character skills on behavior translate into differences in success in the beauty contest, in terms of earnings per round, the $\log$ of earnings per round and the per-round probability of winning the contest (where 'winning' is defined to include ties). A 1 standard deviation increase in the Raven test score increases earnings per round by $\$ 0.11$, that is an increase of $6 \%$ relative to the mean, while a 1 standard deviation increase in Factor 2 increases earnings per round by $\$ 0.13$. Thus the effects of cognitive ability and character skills on earnings are of a similar magnitude in a linear model. Consistent with the absence of an effect on choices, Factors 1 and 3 do not have a statistically significant effect on earnings or the probability of winning.

Earnings (\$ per round) Log of earnings Winning probability

Standardized Raven test score

Factor 1

Factor 2

Factor 3

Subject-round observations

$\begin{array}{cc}0.113^{*} & 0.075^{* *} \\ (0.067) & (0.032) \\ 0.031 & 0.001 \\ (0.051) & (0.024) \\ 0.129^{* *} & 0.057^{* *} \\ (0.051) & (0.022) \\ -0.048 & -0.013 \\ (0.047) & (0.021)\end{array}$

2,700
$0.040^{* * *}$

$(0.015)$

$-0.006$

$(0.011)$

$0.023^{* *}$

$(0.010)$

$-0.002$

(0.010)

Notes: The models are linear and estimated using Ordinary Least Squares regressions. The regressions use the 270 subjects whose character skills we measured, observed for 10 rounds. We standardize the Raven test scores using these 270 subjects. All models include an intercept and a dummy for whether subjects are own-matched high cognitive ability or own-matched low cognitive ability. When taking the log of per-round earnings, we add $\$ 0.50$ to earnings in each round (the show-up fee of $\$ 5$ divided by the number of rounds) to avoid taking the log of 0 . 'Winning' is defined to include a tie with one or both other group members. The statistical significances of the coefficient estimates in the per-round winning probability model are robust to estimating a probit model. Heteroskedasticity-consistent standard errors with clustering at the group level are shown in parentheses. ${ }^{*},{ }^{* *}$ and $^{* * *}$ denote significance at the $10 \%, 5 \%$ and $1 \%$ levels (2-sided tests).

Table 9: Effects of cognitive ability and character skills on per-round earnings and winning probability.

\subsubsection{Learning at the group level}

Our reduced form analysis concludes with an examination of the influence of cognitive ability and character skills on learning at the group level. In particular, we look at the effect of grouplevel averages of cognitive ability and character skills on how close our groups of 3 subjects come to equilibrium play toward the end of the 10 rounds. We analyze only behavior, since average earnings must always be $\$ 2$ per round at the group level.

Table 10 reports the results of regressions of group-level average choices in round 10, rounds 9 and 10, and rounds 8-10, on the group-level averages of cognitive ability and Factors 1-3. We find that cognitive ability and character skills influence learning at the group level: groups with higher cognitive ability on average and higher Factor 2 on average, which captures higher agreeableness and emotional stability, end up closer to the Nash equilibrium in the last few rounds. For instance, a 1 unit increase in a group's average standardized Raven test score 
lowers the group's average choice by 5.0 in the last 3 rounds, while a 1 unit increase in a group's average Factor 2 lowers the group's average choice by 3.8. ${ }^{37}$ These reductions represent decreases of $62 \%$ and $48 \%$, respectively, in choices relative to the mean in the last 3 rounds. Once again, Factors 1 and 3 do not have statistically significant effects.

\begin{tabular}{lccc}
\hline \hline & Round 10 & Rounds 9 \& 10 & Rounds 8-10 \\
\cline { 2 - 4 } Group mean of standardized Raven Test score & $-5.059^{* *}$ & $-3.873^{*}$ & $-4.988^{* *}$ \\
& $(2.007)$ & $(2.234)$ & $(2.351)$ \\
Group mean of Factor 1 & 0.159 & 0.125 & 0.378 \\
Group mean of Factor 2 & $(1.568)$ & $(1.657)$ & $(1.821)$ \\
Group mean of Factor 3 & $-5.423^{* * *}$ & $-4.005^{* * *}$ & $-3.845^{* * *}$ \\
& $(1.871)$ & $(1.268)$ & $(1.376)$ \\
Group-round observations & -0.744 & -0.639 & 0.404 \\
& $(1.467)$ & $(1.376)$ & $(1.508)$ \\
\cline { 2 - 4 } & & & 180 \\
\hline
\end{tabular}

Notes: The models are linear and estimated using Ordinary Least Squares regressions. The regressions use the 270 subjects whose character skills we measured, giving 90 groups observed in round 10, rounds 9 and 10, or rounds 8-10. We standardize the Raven test scores using these 270 subjects, and we calculate group means of the scores standardized at the individual level. All models include an intercept and a dummy for whether groups are own-matched high cognitive ability or own-matched low cognitive ability (the coefficients on the dummy are not statistically significantly different from 0). Heteroskedasticity-consistent standard errors with clustering at the group level are shown in parentheses. ${ }^{*},{ }^{* *}$ and ${ }^{* * *}$ denote significance at the $10 \%, 5 \%$ and $1 \%$ levels $(2$-sided tests).

Table 10: Effects of group-level mean cognitive ability and character skills on group-level mean $p$-beauty contest choices in the last few rounds.

\subsection{Level- $k$ comparison of cognitive ability and character skills}

Last, we compare the effects of cognitive ability and character skills on the adoption of level- $k$ choice rules. In a similar vein to the reduced form analysis reported in Section 6.2.2, we allow the probabilities of adopting the level- $k$ choice rules to vary in subjects' score in the Raven test and their scores on the three factors that capture character skills.

To do this, we modify our structural level- $k$ model of learning from Section 5.1. As before, this modified model includes five fixed level- $k$ learner types with $k \in\{0,1,2,3,4\}$, who follow the level- $k$ choice rule in all rounds $r \geq 2$. We exclude the four rule learner types that were also included in Section 5.1. ${ }^{38}$ A subject's probability of being each of the five learner types depends on her cognitive ability and character skills as follows:

$$
\operatorname{Pr}\left(k \mid \mathbf{z}_{i g}\right)=\frac{\exp \left(\boldsymbol{\lambda}_{k} \mathbf{z}_{i g}\right)}{\sum_{j=0}^{4} \exp \left(\boldsymbol{\lambda}_{j} \mathbf{z}_{i g}\right)},
$$

where $i g$ identifies the subject (see Section 5.1), and $\mathbf{z}_{i g}$ is a vector containing the subject's

\footnotetext{
${ }^{37}$ Note that the standard deviation of the group-level mean Raven test score is 0.84 , while the standard deviation of the group-level mean Factor 2 is 0.54 . The first standard deviation is higher because subjects are matched by cognitive ability.

${ }^{38}$ We do this due to empirical difficulties encountered when estimating the effects of cognitive ability and character skills on type probabilities in a model with many distinct types.
} 
standardized Raven test score, the subject's scores on Factors 1-3, and a dummy for whether the subject is own-matched high cognitive ability or own-matched low cognitive ability. $\mathbf{z}_{i g}$ further includes an element that equals unity for all subjects, and therefore the model includes a full set of learner type-specific intercepts. We impose the identifying normalization $\boldsymbol{\lambda}_{1}=\mathbf{0}$. In all other respects, the modified model is identical to the preferred specification in Section 5.1. Using the 270 subjects whose character skills we measured, observed for 10 rounds, we estimate the 30 model parameters: 24 parameters that appear in the type probability functions; and 6 parameters of the $t$-distribution. Section 5.2 describes the Maximum Likelihood estimation routine.

\begin{tabular}{|c|c|c|c|c|}
\hline \multicolumn{5}{|c|}{ Average level- $k$ choice rule } \\
\hline \multirow[b]{2}{*}{ Baseline } & \multicolumn{4}{|c|}{ Average marginal effects } \\
\hline & $\begin{array}{c}\text { Standardized } \\
\text { Raven test score }\end{array}$ & Factor 1 & Factor 2 & Factor 3 \\
\hline $\begin{array}{l}1.832^{* * *} \\
(0.065)\end{array}$ & $\begin{array}{l}0.264^{* * *} \\
(0.097)\end{array}$ & $\begin{array}{r}-0.038 \\
(0.067)\end{array}$ & $\begin{array}{l}0.160^{* *} \\
(0.070)\end{array}$ & $\begin{array}{l}0.131^{*} \\
(0.068)\end{array}$ \\
\hline \multicolumn{5}{|c|}{ Average probability of following either the L0 or L1 choice rule } \\
\hline \multirow[b]{2}{*}{ Baseline } & \multicolumn{4}{|c|}{ Average marginal effects } \\
\hline & $\begin{array}{c}\text { Standardized } \\
\text { Raven test score }\end{array}$ & Factor 1 & Factor 2 & Factor 3 \\
\hline $\begin{array}{l}0.422^{* * *} \\
(0.036)\end{array}$ & $\begin{array}{l}-0.113^{* *} \\
(0.058)\end{array}$ & $\begin{array}{r}-0.004 \\
(0.038)\end{array}$ & $\begin{array}{c}-0.073^{* *} \\
(0.036)\end{array}$ & $\begin{array}{r}-0.044 \\
(0.036)\end{array}$ \\
\hline
\end{tabular}

Notes: The estimation uses the 270 subjects whose character skills we measured, observed for 10 rounds. We standardized the Raven test scores using these 270 subjects. The baseline average level- $k$ choice rule was obtained by computing the average level- $k$ choice rule for each subject, conditional on $\mathbf{z}_{i g}$ (i.e., on the subject's standardized Raven test score, the subject's scores on Factors 1-3, and a dummy for whether the subject is own-matched high cognitive ability or own-matched low cognitive ability), and then averaging over the subjects. The baseline average probability of following either the L0 or L1 choice rule was obtained by computing the probability that each subject follows either the L0 or L1 choice rule, conditional on $\mathbf{z}_{i g}$, and then averaging over the subjects. The reported marginal effects are averages of the individual-level marginal effects (obtained using differentiation). The matching group dummy did not have a statistically significant effect on the average level- $k$ choice rule or on the average probability of following either the L0 or L1 choice rule. Tests for the significance of the baseline quantities are 1-sided, while all other tests are 2 -sided. Standard errors are shown in parentheses. ${ }^{*},{ }^{* *}$ and ${ }^{* * *}$ denote significance at the $10 \%, 5 \%$ and $1 \%$ levels.

Table 11: Effects of cognitive ability and character skills on level- $k$ choice rules.

Our discussion focuses on Table 11, which shows how cognitive ability and character skills affect the average level- $k$ choice rule and the average probability of following either the L0 or L1 choice rule. Looking first at the top panel of Table 11, we see that both cognitive ability and character skills influence the level- $k$ choice rules that our subjects adopt. Linearizing the average marginal effects reported in the top panel, a 1 standard deviation increase in the Raven test score raises the average level- $k$ choice rule by 0.26 , while a 1 standard deviation increase in Factor 2, which captures an increase in agreeableness and emotional stability, raises the average level- $k$ choice rule by 0.16 . These are increases of $14 \%$ and $9 \%$, respectively, relative to the baseline average level- $k$ choice rule of 1.83 . Thus, the impact of cognitive ability on the average level- $k$ choice rule is about $65 \%$ bigger than that of character skills operating through Factor 2. 
Looking next at the bottom panel of Table 11, we see that the Raven test score and Factor 2 also significantly decrease (at the $5 \%$ level) the average probability of following either the L0 or L1 choice rule. Finally, we note that Factor 3, which captures openness, extraversion and Consideration of Future Consequences, also increases the average level- $k$ choice rule (at the $10 \%$ level), but does not have a statistically significant effect on the average probability of following either the L0 or L1 choice rule.

\section{Conclusion}

Cognitive ability and character skills vary greatly across the population. Our analysis shows that cognition and character affect behavior and learning in a strategic environment with repeated interaction: cognitive ability and character skills help to drive observed heterogeneity in choices and earnings, and strongly predict how quickly groups of agents learn to play equilibrium.

Our finding that more cognitively able, more agreeable and more emotionally stable people perform better and learn faster is important for understanding how boundedly rational people might operate in real-world environments that involve some element of strategic interaction. Our results are also relevant when interpreting close-to-equilibrium behavior: even if average behavior mimics equilibrium play quite closely after some period of learning, low cognitive ability agents might nonetheless be earning substantially less than their high cognitive ability counterparts, with potentially significant implications for fairness and efficiency.

Our findings raise potentially far-reaching practical and ethical questions. For instance: How much protection should public policy afford to slow learners when they operate in markets, especially newer markets in which some participants have price-setting power? How can the design of institutions and mechanisms take into account the impact of bounded rationality on how agents learn to behave in the strategic environment implied by the rules of the institution or mechanism? Is redistribution appropriate to correct for differences in outcomes when people of different cognitive abilities and character skills interact repeatedly? Our findings also link to a wider debate about how clever agents could create environments and mechanisms designed to exploit learning deficiencies (Sobel, 2000, p. 259). In our context, more cognitively able agents may expend resources to ensure that they interact with those less cognitively able. In addition to being socially wasteful, such efforts have the potential to increase income inequality.

We leave it to future research to investigate the merits of interventions, such as training and advice, legal protections and redistributive policies, designed to reduce the performance gap between heterogeneous agents who interact repeatedly or to mitigate the impact of differences in learning speed. 


\section{Appendix}

\section{A Effect of allocation to cognitive ability type}

This paper shows that subjects higher in cognitive ability choose lower numbers and earn more. In this appendix, we consider whether these results could be driven by an effect of allocation to cognitive ability type per se on behavior.

First, we note that the within matching group effects of cognitive ability on behavior that we describe in Section 6 cannot be driven by differences in the allocation to cognitive ability type. In particular, within the set of subjects who were matched into groups of 3 high cognitive ability subjects, an increase in cognitive ability influences behavior by reducing mean choices (the effect is substantial and significant at the 1\% level - see Section 6.2.2). These own-matched high ability subjects all share the same cognitive ability type allocation.

Next, we show that the allocation to cognitive ability type did not have a statistically significant effect on behavior. Thus, we find no evidence that the allocation to cognitive ability type encouraged or discouraged effort. Recall that each subject was allocated to cognitive ability type according to whether her test score was in the top or bottom half of the distribution of scores in her session (see Section 3.2). To test whether the allocation to cognitive ability type per se affected behavior, we regress mean $p$-beauty contest choices and earnings across the 10 rounds on cognitive ability type controlling for a subject's own test score by including a full set of Raven test score dummies (this allows a fully flexible non-linear control for a subject's own cognitive ability). We use only the 445 subjects whose Raven test scores lie in the range of overlap where, conditioning on a given score, some subjects were allocated to the high cognitive ability type and others to the low ability type. The range of overlap arises because the session median Raven test score varied from 37.0 to $43.5 .^{39}$

Table 12 reports the results of these regressions. The regressions in the 'Any' column use all the 445 subjects whose Raven test scores lie in the range of overlap. Since the matching procedure implies that the allocation to cognitive ability type influenced the proportion of high ability opponents on average, these regressions control for the cognitive ability of opponents by including a full set of dummies for the proportion (1, 0.5 or 0$)$ of high ability opponents. The next three columns repeat the exercise, restricting attention to subjects facing a given proportion of high ability opponents (the sum of such subjects is less than 445 because the three ranges of overlap calculated conditional on the proportion of high ability opponents are different from each other, with the union given by the unconditional range of overlap).

Looking at the 'Any' column in Table 12, we see that being allocated to the high ability type increases choices and earnings on average, but the effects are not statistically significant. The next three columns, which condition on the proportion of high ability opponents, also show no statistically significant effects. We also note that the signs of the estimated coefficients vary and that the magnitudes are not monotonic in the proportion of high ability opponents. Table 13 shows similar results when we restrict attention only to the first round or to the second round.

Recall that the mean choice of high cognitive ability subjects is 2.2 lower than that of low

\footnotetext{
${ }^{39}$ Figure 1(b) in Section 3.2 shows the densities of Raven test scores for high and low ability subjects separately and thus illustrates the range of overlap in the middle cognitive ability range.
} 


\begin{tabular}{|c|c|c|c|c|}
\hline & \multicolumn{4}{|c|}{ Proportion of high cognitive ability opponents } \\
\hline & Any & 1 & 0.5 & 0 \\
\hline Effect on mean choices & $\begin{array}{l}0.978 \\
(0.957)\end{array}$ & $\begin{array}{l}0.737 \\
(1.383)\end{array}$ & $\begin{array}{l}2.305 \\
(1.405)\end{array}$ & $\begin{array}{r}-0.490 \\
(2.022)\end{array}$ \\
\hline Effect on earnings ( $\$$ per round $)$ & $\begin{array}{l}0.143 \\
(0.139)\end{array}$ & $\begin{array}{r}-0.020 \\
(0.237)\end{array}$ & $\begin{array}{r}-0.071 \\
(0.257)\end{array}$ & $\begin{array}{l}0.266 \\
(0.211)\end{array}$ \\
\hline Subject-round observations & 4,450 & 1,070 & 610 & 900 \\
\hline
\end{tabular}

Notes: The models are linear and estimated using Ordinary Least Squares regressions. All models include a full set of Raven test score dummies, which control for a subject's own cognitive ability, and an intercept. The regressions in the 'Any' column use the 445 subjects (observed for 10 rounds) whose Raven test scores lie in the range of overlap where, conditioning on a given score, some subjects were allocated to the high cognitive ability type and others to the low ability type (see Section 3.2). These regressions control for the cognitive ability of opponents using a full set of dummies for the proportion (1, 0.5 or 0$)$ of high ability opponents. The next three columns repeat the exercise, restricting attention to subjects facing a given proportion of high ability opponents (the sum of such subjects is less than 445 because the three ranges of overlap calculated conditional on the proportion of high ability opponents are different from each other, with the union given by the unconditional range of overlap). The choice regressions control for previous group behavior by including the mean group choice in the previous round and the square of mean group choice in the previous round. Heteroskedasticity-consistent standard errors, with clustering at the group level, are shown in parentheses. ${ }^{*},{ }^{* *}$ and ${ }^{* * *}$ denote significance at the $10 \%, 5 \%$ and $1 \%$ levels (2-sided tests).

Table 12: Effect of allocation to high cognitive ability type (all rounds).

ability subjects (see Section 4.2.1). Monte Carlo simulations show that if half of this difference was due to a negative effect on choices of being allocated to the high ability type, then there would be a less than $1 \%$ chance of estimating an effect of being allocated to the high ability type that is greater than or equal to our actual estimate of $0.978 .^{40}$

Finally, we note that the range of overlap is sufficiently large to detect effects of cognitive ability. For instance, if we estimate the effect of cognitive ability on choices within the 108 own-matched high ability subjects whose Raven test scores lie in the range of overlap, we find a substantial negative effect of cognitive ability on choices, significant at the $1 \%$ level, thus replicating the finding from Section 6.2.2 described in the second paragraph of this section.

\footnotetext{
${ }^{40}$ The Monte Carlo simulations use a data generation process based on the observed data.
} 


\begin{tabular}{|c|c|c|c|c|}
\hline \multicolumn{5}{|c|}{ Round 1} \\
\hline & \multicolumn{4}{|c|}{ Proportion of high cognitive ability opponents } \\
\hline & Any & 1 & 0.5 & 0 \\
\hline Effect on mean choices & $\begin{array}{l}3.815 \\
(2.672)\end{array}$ & $\begin{array}{l}0.607 \\
(3.976)\end{array}$ & $\begin{array}{l}4.527 \\
(6.461)\end{array}$ & $\begin{array}{l}7.268^{*} \\
(4.103)\end{array}$ \\
\hline Effect on earnings $(\$)$ : & $\begin{array}{l}0.078 \\
(0.406)\end{array}$ & $\begin{array}{r}-0.062 \\
(0.612)\end{array}$ & $\begin{array}{l}0.422 \\
(0.809)\end{array}$ & $\begin{array}{r}-0.201 \\
(0.629)\end{array}$ \\
\hline \multirow[t]{4}{*}{ Subject-round observations } & 445 & 107 & 61 & 90 \\
\hline & \multicolumn{4}{|c|}{ Round 2} \\
\hline & \multicolumn{4}{|c|}{ Proportion of high cognitive ability opponents } \\
\hline & Any & 1 & 0.5 & 0 \\
\hline Effect on mean choices & $\begin{array}{l}0.606 \\
(2.331)\end{array}$ & $\begin{array}{l}5.517 \\
(3.949)\end{array}$ & $\begin{array}{l}0.477 \\
(5.496)\end{array}$ & $\begin{array}{r}-5.025 \\
(3.095)\end{array}$ \\
\hline Effect on earnings $(\$)$ : & $\begin{array}{l}0.041 \\
(0.421)\end{array}$ & $\begin{array}{r}-0.701 \\
(0.673)\end{array}$ & $\begin{array}{l}0.274 \\
(0.717)\end{array}$ & $\begin{array}{l}0.543 \\
(0.702)\end{array}$ \\
\hline Subject-round observations & 445 & 107 & 61 & 90 \\
\hline
\end{tabular}

Notes: See the notes to Table 12. Subjects are observed for a single round (round 1 or round 2). Heteroskedasticityconsistent standard errors, with clustering at the group level (apart from the round 1 choice regressions, since within-group first round choices are independent), are shown in parentheses. ${ }^{*},{ }^{* *}$ and ${ }^{* * *}$ denote significance at the $10 \%, 5 \%$ and $1 \%$ levels (2-sided tests).

Table 13: Effect of allocation to high cognitive ability type (Round 1 and Round 2).

\section{B Further goodness of fit analysis}

Tables 14 and 15 provide further evidence that our structural level- $k$ model of learning fits well. Table 14 reports values of $\log$ likelihoods and of sums of squared deviations of choices, earnings and convergence statistics computed from simulated choices, which together show that our model fits the observed data well. The table also provides evidence from Vuong tests (for non-nested model comparisons) or likelihood ratio tests (for nested model comparisons) that our preferred specification fits better than various alternative specifications. We now provide a brief description of each of the alternative specifications:

- AS1: Once a L $k-(k+1)$ rule learner switches to the level- $(k+1)$ choice rule, she never switches back. In each round $r \geq 3$, one-eighth of the $L k-(k+1)$ rules learners switch to the level- $(k+1)$ choice rule; therefore, as in the preferred specification, in round 2 they all follow the level- $k$ choice rule and by round 10 they all follow the $L k-(k+1)$ choice rule.

- AS2: The normal distribution replaces the $t$-distribution in the model of the choice process.

- AS3: The choices of 100 come from the same $t$-distribution as for the other choices (instead of the probability of a choice of 100 coming from the round-specific but cognitive ability independent empirical frequency observed in the sample).

- AS4: Subjects following the level- $k$ choice rule for $k>0$ take into account the effect of their own choice on the target, and understand that subjects following lower level- $k$ choices rules do so as well. For $k>0, \mu\left(k, \mathbf{x}_{g, r-1}\right)$ is thus given by a lower fraction of $\bar{x}_{g, r-1}$ than in the preferred specification. 
- AS5: Rule learner types are not included in the model (so there are just five standard level- $k$ learner types, with $k \in\{0,1,2,3,4\}$, who follow the level- $k$ choice rule in all rounds $r \geq 2$ ).

- AS6: The probabilities of learner types are not allowed to vary with subjects' own cognitive ability or with whether subjects are in own-matched or cross-matched groups.

- AS7: The probabilities of learner types are not allowed to vary with whether subjects are in own-matched or cross-matched groups (but are allowed to vary with subjects' own cognitive ability).

- AS8: The Experience-Weighted Attraction (EWA) learning model of Camerer and Ho (1999) replaces the level- $k$ model of learning. ${ }^{41}$

Table 15 shows that our structural level- $k$ model of learning continues to perform well out of sample. In particular, the table reports how the model performs when we simulate choices for all rounds, but estimate the model's parameters using only the data from rounds 1-8 (3rd and 4th columns), compared to performance using parameters estimated from all the data (1st and 2nd columns). In each case, we provide statistics of fit computed from the simulated choices for all rounds and for rounds 9 and 10 alone.

\footnotetext{
${ }^{41}$ We "burn in" the initial attractions using the choice probabilities given by an ordered probit model estimated on the first round data (for discussion see Ho et al., 2007, footnote 6). We set the initial experience weight, $N(0)$, to unity: Ho et al. (2007, p. 182) impose the same restriction, while noting that the influence of this parameter decreases rapidly over rounds and most experimental subjects have weak priors. We estimate a total of 16 parameters: that is the 4 remaining parameters, $\phi, \lambda, \rho$ and $\delta$, for own-matched high cognitive ability subjects, cross-matched high ability subjects, cross-matched low ability subjects and own-matched low ability subjects. The poor fit of the EWA model shown in Table 14 (AS8) is consistent with previous estimations of the EWA model using beauty contest data (see Camerer and Ho, 1999, Table 1 and the discussion at pp. 863-864). Despite the poor fit of the EWA model, we briefly discuss differences in parameter estimates by cognitive ability type. High ability subjects have a statistically significantly lower discount factor for previous attractions, $\phi$, and a statistically significantly higher attraction sensitivity, $\lambda$. We find no statistically significant differences by cognitive ability type in the discount factor for experience, $\rho$, or in the relative weight given to belief-based learning versus reinforcement learning in updating attractions, $\delta$. The latter result is perhaps not surprising because whenever beliefs are given non-zero weight, i.e., $\delta>0$, attraction updating requires a subject to know her own payoff in the previous round and to compute all forgone payoffs. In other words, provided $\delta>0$, the information required to follow the EWA learning rule does not depend on the value of $\delta$.
} 


\begin{tabular}{|c|c|c|c|c|c|}
\hline & \multirow{2}{*}{$\begin{array}{c}\text { Preferred } \\
\text { specification }\end{array}$} & \multicolumn{4}{|c|}{ Alternative specifications } \\
\hline & & AS1 & AS2 & AS3 & AS4 \\
\hline \multicolumn{6}{|l|}{ Sum of squared deviations of choices: } \\
\hline Own-matched high ability subjects & 17.1 & 55.5 & 16.8 & 32.0 & 14.6 \\
\hline Own-matched low ability subjects & 30.6 & 125.0 & 39.2 & 57.0 & 35.1 \\
\hline Cross-matched high ability subjects & 22.5 & 84.41 & 19.7 & 48.2 & 16.1 \\
\hline Cross-matched low ability subjects & 24.7 & 53.7 & 51.3 & 29.0 & 13.4 \\
\hline $\begin{array}{l}\text { Sum of squared deviations of earnings: } \\
\text { Cross-matched high ability subjects }\end{array}$ & 0.190 & 0.220 & 0.269 & 0.224 & 0.287 \\
\hline \multicolumn{6}{|c|}{ Sum of squared deviations of convergence stats: } \\
\hline Own-matched high ability groups & 2.26 & 0.47 & 1.57 & 2.82 & 0.95 \\
\hline Cross-matched groups & 0.53 & 0.08 & 1.77 & 0.71 & 0.43 \\
\hline Own-matched low ability groups & 0.12 & 0.81 & 8.32 & 0.24 & 0.17 \\
\hline Log likelihood & $-21,510$ & $-21,563$ & $-23,302$ & $-21,780$ & $-21,556$ \\
\hline \multirow[t]{3}{*}{$\begin{array}{l}\text { Test against the preferred specification: } \\
\qquad p \text { value }\end{array}$} & - & $0.007^{\mathrm{a}}$ & $0.000^{\mathrm{b}}$ & $0.000^{\mathrm{a}}$ & $0.054^{\mathrm{a}}$ \\
\hline & & \multicolumn{4}{|c|}{ Alternative specifications } \\
\hline & & AS5 & AS6 & AS7 & AS8 \\
\hline \multicolumn{6}{|l|}{ Sum of squared deviations of choices: } \\
\hline Own-matched high ability subjects & & 40.8 & 28.5 & 12.2 & 755.2 \\
\hline Own-matched low ability subjects & & 76.6 & 75.5 & 32.7 & 435.3 \\
\hline Cross-matched high ability subjects & & 44.5 & 15.7 & 34.9 & 574.4 \\
\hline Cross-matched low ability subjects & & 42.5 & 30.1 & 19.3 & 406.8 \\
\hline $\begin{array}{l}\text { Sum of squared deviations of earnings: } \\
\text { Cross-matched high ability subjects }\end{array}$ & & 0.246 & 0.481 & 0.216 & 0.585 \\
\hline \multicolumn{6}{|c|}{ Sum of squared deviations of convergence stats: } \\
\hline Own-matched high ability groups & & 3.43 & 9.90 & 4.16 & 57.73 \\
\hline Cross-matched groups & & 0.88 & 0.10 & 0.07 & 79.40 \\
\hline Own-matched low ability groups & & 0.32 & 0.46 & 0.38 & 17.43 \\
\hline Log likelihood & & $-21,599$ & $-21,534$ & $-21,522$ & $-26,142$ \\
\hline $\begin{array}{l}\text { Test against the preferred specification: } \\
\qquad p \text { value }\end{array}$ & & $0.000^{\mathrm{b}}$ & $0.003^{\mathrm{b}}$ & $0.104^{\mathrm{b}}$ & $0.000^{\mathrm{a}}$ \\
\hline
\end{tabular}

Notes: Descriptions of each alternative specification are in the text of Appendix B. Squared deviations of choices and earnings (in dollars) were computed in each round from the simulated choices generated as described in the notes to Figure 7, and then summed over rounds. By construction, the sum of squared deviations of earnings: (i) is identical for cross-matched high ability and low ability subjects; and (ii) is zero for both own-matched high ability and low ability subjects. Squared deviations of convergence statistics were computed for each of the 3 proportions of equilibrium and close-to-equilibrium play in Table 3, and then summed and multiplied by 100 .

a 2 -sided Vuong test.

${ }^{\mathrm{b}}$ Likelihood ratio test.

Table 14: Goodness of fit: preferred specification vs. alternatives. 


\begin{tabular}{|c|c|c|c|c|}
\hline & \multicolumn{2}{|c|}{$\frac{\text { Estimation using all rounds }}{\text { Goodness of fit: }}$} & \multicolumn{2}{|c|}{$\frac{\text { Estimation using rounds 1-8 }}{\text { Goodness of fit: }}$} \\
\hline & All rounds & Rounds $9 \& 10$ & All rounds & Rounds $9 \& 10$ \\
\hline \multicolumn{5}{|l|}{ Sum of squared deviations of choices: } \\
\hline Own-matched high ability subjects & 17.1 & 2.48 & 12.7 & 0.36 \\
\hline Own-matched low ability subjects & 30.6 & 1.17 & 34.3 & 4.07 \\
\hline Cross-matched high ability subjects & 22.5 & 1.17 & 25.1 & 2.24 \\
\hline Cross-matched low ability subjects & 24.7 & 1.11 & 18.5 & 2.08 \\
\hline \multicolumn{5}{|l|}{ Sum of squared deviations of earnings: } \\
\hline \multicolumn{5}{|c|}{ Sum of squared deviations of convergence statistics: } \\
\hline Own-matched high ability groups & - & 2.26 & - & 0.50 \\
\hline Cross-matched groups & - & 0.53 & - & 0.05 \\
\hline Own-matched low ability groups & - & 0.12 & - & 0.13 \\
\hline Log likelihood & $-21,510$ & - & $-21,553$ & - \\
\hline
\end{tabular}

Notes: The statistics were computed in the same way as described in Table 14, except that the 2nd and 4th columns report the statistics computed only for rounds 9 and 10 , while the 3rd and 4 th columns were computed from simulated choices based on an estimate of the parameter vector $\boldsymbol{\theta}$ obtained using only the data from rounds 1-8. The statistics in the 4 th column are therefore out-of-sample quantities.

Table 15: Goodness of fit: in-sample vs. out-of-sample.

\section{Disaggregating choices and earnings statistics for cross-matched subjects}

In Section 4.2.3 we found that within cross-matched groups: high and low ability subjects choose similarly on average; and high ability subjects earn more than low ability subjects. Recall, a cross-matched group is made up of either 2 high ability subjects and 1 low ability subject or 1 high ability subject and 2 low ability subjects. Figure 11(a) shows that, in both types of crossmatched group, high and low ability subjects choose similarly on average. More formally, over the 10 rounds, the difference between the average choices of high and low ability subjects in crossmatched groups with 2 high ability subjects is not statistically significant (2-sided $p=0.543) .{ }^{42}$ Similarly, over the 10 rounds, the difference between the average choices of high and low ability subjects in cross-matched groups with 1 high ability subject is not statistically significant (2sided $p=0.286)$.

Figure 11(b) shows that, in both types of cross-matched group, high ability subjects tend to earn more than low ability subjects. Over the 10 rounds, high ability subjects in cross-matched groups with 2 high ability subjects earn $\$ 2.92$ more than low ability subjects in the same type of cross-matched group (2-sided $p=0.173)$. Similarly, high ability subjects in cross-matched groups with 1 high ability subject earn $\$ 5.10$ more than low ability subjects in the same type of cross-matched group (2-sided $p=0.013)$.

\footnotetext{
${ }^{42}$ Throughout Appendix C, all statistical tests are based on Ordinary Least Squares regressions and use heteroskedasticity-consistent standard errors. We cluster at the group level to allow for within-group nonindependence. The regressions use 10 rounds of observations on either the 165 subjects in cross-matched groups with 2 high ability subjects or the 165 subjects in cross-matched groups with 1 high ability subject.
} 


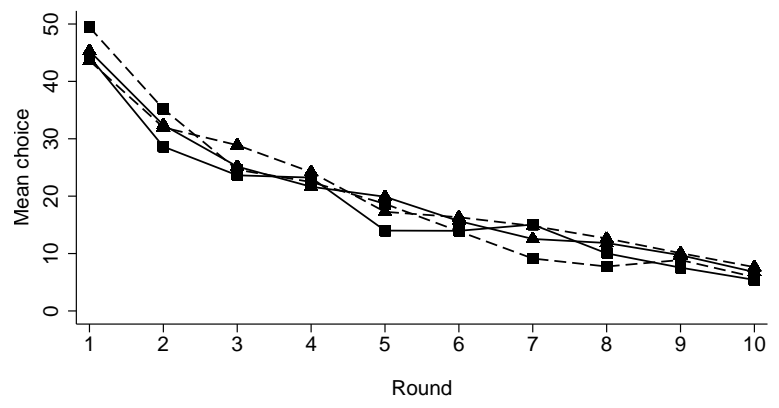

(a) Round-by-round means of choices.

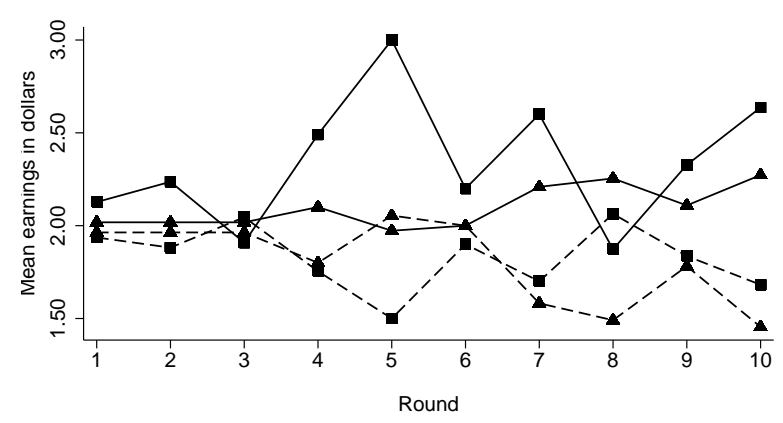

(b) Round-by-round means of earnings.

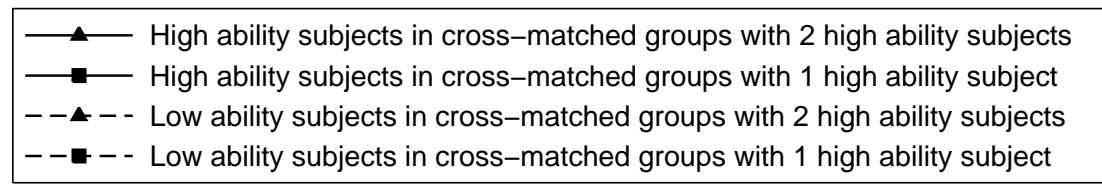

Figure 11: Disaggregated $p$-beauty contest choices and earnings of cross-matched subjects.

\section{Disaggregating convergence statistics for cross-matched groups}

Table 16 shows the frequencies of equilibrium and close-to-equilibrium play in the final 2 rounds of the experiment separately for cross-matched groups with 2 high ability subjects and for crossmatched groups with 1 high ability subject. We note that there are no statistically significant differences between the 2 types of cross-matched groups in the frequencies of equilibrium or close-to-equilibrium play.

\section{Equilibrium $\quad$ Group mean $\leq 1 \quad$ Group mean $\leq 2$}

\section{Observed proportions:}

Cross-matched groups with 2 high ability subjects

Cross-group differences in proportions:

Cross-matched groups with 2 high ability subjects vs.

Cross-matched groups with 1 high ability subject

$\begin{array}{rrr}0.036 & 0.000 & -0.045 \\ (0.065) & (0.081) & (0.086)\end{array}$

Notes: The table is based on 220 group-round observations ( 55 cross-matched groups with 2 high ability subjects and 55 cross-matched groups with 1 high ability subject, observed in rounds 9 and 10). The first column reports the proportion of group-round observations in rounds 9 and 10 in which all 3 group members choose 0 . The second (third) column reports the proportion of group-round observations in rounds 9 and 10 in which the mean choice of the 3 group members is less than or equal to 1 (2). The statistical tests of differences in proportions are based on Ordinary Least Squares regressions. Heteroskedasticity-consistent standard errors (with clustering at the group level) are shown in parentheses. ${ }^{*},{ }^{* *}$ and ${ }^{* * *}$ denote significance at the $10 \%, 5 \%$ and $1 \%$ levels $(2$-sided tests).

Table 16: Proportions of equilibrium and close-to-equilibrium play in rounds 9 and 10 , split by type of cross-matched group. 


\section{References}

Agranov, M., Caplin, A., and Tergiman, C. (2011). The process of choice in guessing games. Mimeo, Caltech

Agranov, M., Potamites, E., Schotter, A., and Tergiman, C. (2012). Beliefs and endogenous cognitive levels: An experimental study. Games and Economic Behavior, 75(2): 449-463

Al-Ubaydli, O., Jones, G., and Weel, J. (2013). Patience, cognitive skill, and coordination in the repeated stag hunt. Journal of Neuroscience, Psychology, and Economics, 6(2): 71-96

Alexander, J.R.M. and Smales, S. (1997). Intelligence, learning and long-term memory. Personality and Individual Differences, 23(5): 815-825

Almlund, M., Duckworth, A.L., Heckman, J., and Kautz, T. (2011). Personality psychology and economics. In E. Hanushek, S. Machin, and L. Woessman, editors, Handbook of the Economics of Education, Vol. 4, 1-181. Amsterdam: Elsevier

Arbak, E. and Villeval, M.C. (2013). Voluntary leadership: motivation and influence. Social Choice and Welfare, 40(3): 635-662

Bayer, R.C. and Renou, L. (2012). Logical abilities and behavior in strategic-form games. Mimeo, University of Leicester

Berndt, E., Hall, B., Hall, R., and Hausman, J. (1974). Estimation and inference in nonlinear statistical models. Annals of Economic and Social Measurement, 3(4): 653-665

Boone, C., De Brabander, B., Carree, M., de Jong, G., van Olffen, W., and van Witteloostuijn, A. (2002). Locus of control and learning to cooperate in a prisoner's dilemma game. Personality and Individual Differences, 32(5): 929-946

Borghans, L., Duckworth, A.L., Heckman, J.J., and ter Weel, B. (2008). The economics and psychology of personality traits. Journal of Human Resources, 43(4): 972-1059

Borghans, L., Golsteyn, B.H.H., Heckman, J., and Humphries, J.E. (2011). Identification problems in personality psychology. Personality and Individual Differences, 51(3): $315-320$

Boudreau, J.W., Boswell, W.R., Judge, T.A., and Bretz Jr., R.D. (2001). Personality and cognitive ability as predictors of job search among employed managers. Personnel Psychology, 54(1): 25-50

Brañas-Garza, P., García-Muño, T., and Hernán, R. (2012). Cognitive effort in the beauty contest game. Journal of Economic Behavior \&3 Organization, 83(2): 254-260

Brandstätter, H. and Königstein, M. (2001). Personality influences on ultimatum bargaining decisions. European Journal of Personality, 15(S1): S53-S70

Brocas, I., Carrillo, J.D., Wang, S.W., and Camerer, C.F. (forthcoming). Imperfect choice or imperfect attention? Understanding strategic thinking in private information games. Review of Economic Studies

Burks, S.V., Carpenter, J.P., Goette, L., and Rustichini, A. (2009). Cognitive skills affect economic preferences, strategic behavior, and job attachment. Proceedings of the National Academy of Sciences, 106(19): 7745-7750

Burks, S.V., Lewis, C., Kivi, P., Wiener, A., Anderson, J.E., Götte, L., DeYoung, C.G., and Rustichini, A. (2014). Moving ahead by thinking backwards: Cognitive skills, personality, and economic preferences in collegiate success. IZA Discussion Paper 7952

Burnham, T., Cesarini, D., Johannesson, M., Lichtenstein, P., and Wallace, B. (2009). Higher cognitive ability is associated with lower entries in a p-beauty contest. Journal of Economic Behavior \& Organization, 72(1): 171-175

Camerer, C. and Ho, H.T. (1999). Experience-weighted attraction learning in normal form games. Econometrica, 67(4): 827-874

Camerer, C.F. (2003). Behavioral game theory: Experiments in strategic interaction. Princeton: Princeton University Press

Camerer, C.F., Ho, T.H., and Chong, J.K. (2004). A cognitive hierarchy model of games. Quarterly Journal of Economics, 119(3): 861-898

Cardella, E. (2012). Learning to make better strategic decisions. Journal of Economic Behavior E Organization, 84(1): 382-392 
Carpenter, P.A., Just, M.A., and Shell, P. (1990). What one intelligence test measures: A theoretical account of the processing in the Raven Progressive Matrices test. Psychological review, 97(3): 404-413

Cattell, R.B. and Butcher, H.J. (1968). The Prediction of Achievement and Creativity. Oxford, England: Bobbs-Merrill

Charness, G., Rustichini, A., and van de Ven, J. (2011). Self-confidence and strategic deterrence. Mimeo, UCSB

Colvin, S.S. (1921). Intelligence and its measurement: A symposium (IV). Journal of Educational Psychology, 12(4): 136-139

Coricelli, G. and Nagel, R. (2009). Neural correlates of depth of strategic reasoning in medial prefrontal cortex. Proceedings of the National Academy of Sciences, 106(23): 9163-9168

Costa-Gomes, M., Crawford, V.P., and Broseta, B. (2001). Cognition and behavior in normal-form games: An experimental study. Econometrica, 69(5): 1193-1235

Costa-Gomes, M.A. and Crawford, V.P. (2006). Cognition and behavior in two-person guessing games: An experimental study. American Economic Review, 96(5): 1737-1768

Costa-Gomes, M.A., Crawford, V.P., and Iriberri, N. (2009). Comparing models of strategic thinking in Van Huyck, Battalio, and Beil's coordination games. Journal of the European Economic Association, 7(2-3): 365-376

Costa-Gomes, M.A. and Weizsäcker, G. (2008). Stated beliefs and play in normal-form games. Review of Economic Studies, 75(3): 729-762

Crawford, V.P., Costa-Gomes, M.A., and Iriberri, N. (2013). Structural models of nonequilibrium strategic thinking: Theory, evidence, and applications. Journal of Economic Literature, 51(1): 5-62

Crawford, V.P. and Iriberri, N. (2007a). Level- $k$ auctions: Can a nonequilibrium model of strategic thinking explain the winner's curse and overbidding in private-value auctions? Econometrica, 75(6): 1721-1770

Crawford, V.P. and Iriberri, N. (2007b). Fatal attraction: Salience, naïveté, and sophistication in experimental "Hide-and-Seek" games. American Economic Review, 97(5): 1731-1750

Cunha, F., Heckman, J.J., and Schennach, S.M. (2010). Estimating the technology of cognitive and noncognitive skill formation. Econometrica, 78(3): 883-931

Daly, M., Harmon, C.P., and Delaney, L. (2009). Psychological and biological foundations of time preference. Journal of the European Economic Association, 7(2-3): 659-669

Danner, D., Hagemann, D., Schankin, A., Hager, M., and Funke, J. (2011). Beyond IQ: A latent state-trait analysis of general intelligence, dynamic decision making, and implicit learning. Intelligence, 39(5): 323-334

Dearborn, W.F. (1921). Intelligence and its measurement: A symposium (XII). Journal of Educational Psychology, 12(4): 210-212

Delaney, L., Harmon, C., and Ryan, M. (2013). The role of noncognitive traits in undergraduate study behaviours. Economics of Education Review, 32: 181-195

DeYoung, C.G., Hirsh, J.B., Shane, M.S., Papademetris, X., Rajeevan, N., and Gray, J.R. (2010). Testing predictions from personality neuroscience brain structure and the Big Five. Psychological Science, 21(6): 820-828

Duckworth, A.L., Peterson, C., Matthews, M.D., and Kelly, D.R. (2007). Grit: Perseverance and passion for long-term goals. Journal of Personality and Social Psychology, 92(6): $1087-1101$

Duffy, J. and Nagel, R. (1997). On the robustness of behaviour in experimental 'beauty contest' games. Economic Journal, 107(445): 1684-1700

Dufwenberg, M., Sundaram, R., and Butler, D.J. (2010). Epiphany in the Game of 21. Journal of Economic Behavior \&3 Organization, 75(2): 132-143

Eysenck, M.W. (1985). Anxiety and cognitive-task performance. Personality and Individual Differences, 6(5): 579-586

Fahr, R. and Irlenbusch, B. (2008). Identifying personality traits to enhance trust between organisations: An experimental approach. Managerial and Decision Economics, 29(6): 469487

Fischbacher, U. (2007). z-Tree: Zurich toolbox for ready-made economic experiments. Experimental Economics, 10(2): 171-178 
Flehmig, H.C., Steinborn, M., Langner, R., and Westhoff, K. (2007). Neuroticism and the mental noise hypothesis: Relationships to lapses of attention and slips of action in everyday life. Psychology Science, 49(4): 343-360

Fouarge, D., Schils, T., and de Grip, A. (2013). Why do low-educated workers invest less in further training? Applied Economics, 45(18): 2587-2601

Frederick, S. (2005). Cognitive reflection and decision making. Journal of Economic Perspectives, 19(4): 25-42

Gebauer, G.F. and Mackintosh, N.J. (2007). Psychometric intelligence dissociates implicit and explicit learning. Journal of Experimental Psychology: Learning, Memory, and Cognition, 33(1): $34-54$

Gill, D. and Prowse, V. (2012). Cognitive ability and learning to play equilibrium: A level- $k$ analysis. MPRA Paper 38317

Gneezy, U., Rustichini, A., and Vostroknutov, A. (2010). Experience and insight in the Race game. Journal of Economic Behavior \&3 Organization, 75(2): 144-155

Goldfarb, A. and Xiao, M. (2011). Who thinks about the competition? Managerial ability and strategic entry in US local telephone markets. American Economic Review, 101(7): 31303161

Gonzalez, C. (2004). Learning to make decisions in dynamic environments: Effects of time constraints and cognitive abilities. Human Factors, 46(3): 449-460

Gray, J. and Thompson, P. (2004). Neurobiology of intelligence: Science and ethics. Nature Reviews Neuroscience, 5(6): 471-482

Heckman, J.J., Humphries, J.E., Veramendi, G., and Urzúa, S. (2014). Education, health and wages. NBER Working Paper 19971

Heckman, J.J. and Kautz, T. (2014). Achievement tests and the role of character in American life. In J.J. Heckman, J.E. Humphries, and T. Kautz, editors, The Myth of Achievement Tests: The GED and the Role of Character in American Life. Chicago: University of Chicago Press

Heckman, J.J., Stixrud, J., and Urzua, S. (2006). The effects of cognitive and noncognitive abilities on labor market outcomes and social behavior. Journal of Labor Economics, 24(3): 411-482

Heineck, G. (2011). Does it pay to be nice? Personality and earnings in the United Kingdom. Industrial and Labor Relations Review, 64(5): 1020-1038

Higgins, D.M., Peterson, J.B., Pihl, R.O., and Lee, A.G.M. (2007). Prefrontal cognitive ability, intelligence, Big Five personality, and the prediction of advanced academic and workplace performance. Journal of Personality and Social Psychology, 93(2): 298-319

Ho, T.H., Camerer, C., and Weigelt, K. (1998). Iterated dominance and iterated best response in experimental "p-beauty contests". American Economic Review, 88(4): 947-969

Ho, T.H., Camerer, C.F., and Chong, J.K. (2007). Self-tuning experience weighted attraction learning in games. Journal of Economic Theory, 133(1): 177-198

Houser, D. and Winter, J. (2004). How do behavioral assumptions affect structural inference? Evidence from a laboratory experiment. Journal of Business 85 Economic Statistics, 22(1): 64-79

Hunter, J.E. and Hunter, R.F. (1984). Validity and utility of alternative predictors of job performance. Psychological Bulletin, 96(1): 72-98

Jensen, A.R. (1989). The relationship between learning and intelligence. Learning and Individual Differences, 1(1): 37-62

John, O.P., Naumann, L.P., and Soto, C.J. (2008). Paradigm shift to the integrative Big Five trait taxonomy: History, measurement, and conceptual issues. In O.P. John, R.W. Robins, and L.A. Pervin, editors, Handbook of personality: Theory and research, 114-158. New York, NY: Guilford Press

John, O.P., Donahue, E.M., and Kentle, R.L. (1991). The Big Five Inventory: Versions 4a and 54. Institute of Personality and Social Research, University of California, Berkeley

Johnson, M.K., Rustichini, A., and MacDonald III, A.G. (2009). Suspicious personality predicts behavior on a social decision-making task. Personality and Individual Differences, 47(1): $30-35$

Jolliffe, I.T. (1995). Rotation of principal components: Choice of normalization constraints. Journal of Applied Statistics, 22(1): 29-35 
Judge, T.A., Higgins, C.A., Thoresen, C.J., and Barrick, M.R. (1999). The Big Five personality traits, general mental ability, and career success across the life span. Personnel Psychology, 52(3): 621-652

Kaiser, H.F. (1960). The application of electronic computers to factor analysis. Educational and Psychological Measurement, 20(1): 141-151

Kaufman, S.B., DeYoung, C.G., Gray, J.R., Brown, J., and Mackintosh, N. (2009). Associative learning predicts intelligence above and beyond working memory and processing speed. Intelligence, 37(4): 374-382

Kurzban, R. and Houser, D. (2001). Individual differences in cooperation in a circular public goods game. European Journal of Personality, 15(S1): S37-S52

Le Coq, C. and Sturluson, J.T. (2012). Does opponents' experience matter? Experimental evidence from a quantity precommitment game. Journal of Economic Behavior 83 Organization, 84(1): 265-277

Levitt, S.D., List, J.A., and Sadoff, S.E. (2011). Checkmate: Exploring backward induction among chess players. American Economic Review, 101(2): 975-90

Lindqvist, E. and Vestman, R. (2011). The labor market returns to cognitive and noncognitive ability: Evidence from the Swedish enlistment. American Economic Journal: Applied Economics, 2(1): 101-128

López, R. (2001). On p-beauty contest integer games. UPF Economics and Business Working Paper No. 608

McDaniel, M.A. (1985). The evaluation of a causal model of job performance: The interrelationships of general mental ability, job experience, and job performance. Doctoral dissertation, George Washington University

Millet, K. and Dewitte, S. (2007). Altruistic behavior as a costly signal of general intelligence. Journal of Research in Personality, 41(2): 316-326

Mueller, G. and Plug, E. (2006). Estimating the effect of personality on male and female earnings. Industrial and Labor Relations Review, 60(1): 3-22

Müller, J. and Schwieren, C. (2012). What can the Big Five Personality Factors contribute to explain Small-Scale Economic Behavior? Tinbergen Institute Discussion Paper 2012-028/1

Nagel, R. (1995). Unraveling in guessing games: An experimental study. American Economic Review, 85(5): 1313-1326

Neeman, Z., Kugler, T., and Vulkan, N. (2013). Personality traits and strategic behavior: Anxiousness, aggressiveness and entry games. Pinhas Sapir Center for Development Discussion Paper No. 7-13

Neisser, U., Boodoo, G., Bouchard Jr, T.J., Boykin, A.W., Brody, N., Ceci, S.J., Halpern, D.F., Loehlin, J.C., Perloff, R., Sternberg, R.J., and Urbina, S. (1996). Intelligence: Knowns and unknowns. American Psychologist, 51(2): 77-101

Nettle, D. and Liddle, B. (2008). Agreeableness is related to social-cognitive, but not socialperceptual, theory of mind. European Journal of Personality, 22(4): 323-335

Nyhus, E.K. and Pons, E. (2005). The effects of personality on earnings. Journal of Economic Psychology, 26(3): 363-384

Offerman, T., Potters, J., and Sonnemans, J. (2002). Imitation and belief learning in an oligopoly experiment. Review of Economic Studies, 69(4): 973-997

Ohtsubo, Y. and Rapoport, A. (2006). Depth of reasoning in strategic form games. Journal of Socio-economics, 35(1): 31-47

Östling, R., Wang, J.T., Chou, E.Y., and Camerer, C.F. (2011). Testing game theory in the field: Swedish LUPI lottery games. American Economic Journal: Microeconomics, 3(3): $1-33$

Palacios-Huerta, I. and Volij, O. (2009). Field centipedes. American Economic Review, 99(4): 1619-1635

Raven, J., Raven, J.C., and Court, J.H. (2000). Manual for Raven's Progressive Matrices and Vocabulary Scales Section 3: Standard Progressive Matrices. San Antonio, TX: Pearson

Roth, A. and Xing, X. (1994). Jumping the gun: Imperfections and institutions related to the timing of market transactions. American Economic Review, 84(4): 992-1044 
Rustichini, A., DeYoung, C.G., Anderson, J., and Burks, S.V. (2012). Toward the integration of personality theory and decision theory in the explanation of economic and health behavior. IZA Discussion Paper 6750

Rydval, O., Ortmann, A., and Ostatnicky, M. (2009). Three very simple games and what it takes to solve them. Journal of Economic Behavior \&3 Organization, 72(1): 589-601

Salgado, J.F. (1997). The Five Factor Model of personality and job performance in the European Community. Journal of Applied Psychology, 82(1): 30-43

Schmidt, F.L. and Hunter, J. (2004). General mental ability in the world of work: Occupational attainment and job performance. Journal of Personality and Social Psychology, 86(1): $162-173$

Schmidt, F.L., Hunter, J.E., and Outerbridge, A.N. (1986). Impact of job experience and ability on job knowledge, work sample performance, and supervisory ratings of job performance. Journal of Applied Psychology, 71(3): 432-439

Schmidt, F.L., Hunter, J.E., Outerbridge, A.N., and Goff, S. (1988). Joint relation of experience and ability with job performance: Test of three hypotheses. Journal of Applied Psychology, 73(1): 46-57

Schnusenberg, O. and Gallo, A. (2011). On cognitive ability and learning in a beauty contest. Journal for Economic Educators, 11(1): 13-24

Seibert, S.E. and Kraimer, M.L. (2001). The Five-Factor Model of personality and career success. Journal of Vocational Behavior, 58(1): 1-21

Sobel, J. (2000). Economists' models of learning. Journal of Economic Theory, 94(2): 241-261

Spector, P.E., Jex, S.M., and Chen, P.Y. (1995). Relations of incumbent affect-related personality traits with incumbent and objective measures of characteristics of jobs. Journal of Organizational Behavior, 16(1): 59-65

Stahl, D.O. (1996). Boundedly rational rule learning in a guessing game. Games and Economic Behavior, 16(2): 303-330

Stahl, D.O. and Wilson, P.W. (1995). On players' models of other players: Theory and experimental evidence. Games and Economic Behavior, 10(1): 218-254

Strathman, A., Gleicher, F., Boninger, D.S., and Scott Edwards, C. (1994). The consideration of future consequences: Weighing immediate and distant outcomes of behavior. Journal of Personality and Social Psychology, 66(4): 742-752

Szymura, B. and Wodniecka, Z. (2003). What really bothers neurotics? In search for factors impairing attentional performance. Personality and Individual Differences, 34(1): 109-126

Unger, J.M., Keith, N., Hilling, C., Gielnik, M.M., and Frese, M. (2009). Deliberate practice among South African small business owners: Relationships with education, cognitive ability, knowledge, and success. Journal of Occupational and Organizational Psychology, 82: $21-24$

Volk, S., Thöni, C., and Ruigrok, W. (2011). Personality, personal values and cooperation preferences in public goods games: A longitudinal study. Personality and Individual Differences, 50(6): 810-815

Webley, P. and Nyhus, E.K. (2013). Economic socialization, saving and assets in European young adults. Economics of Education Review, 33: 19-30

Wechsler, D. (1940). Nonintellective factors in general intelligence. Psychological Bulletin, 37: 444-445

Williams, B.A. and Pearlberg, S.L. (2006). Learning of three-term contingencies correlates with Raven scores, but not with measures of cognitive processing. Intelligence, 34(2): 177-191 